\title{
Recommended screening and preventive practices for long-term survivors after hematopoietic cell transplantation
}

Navneet Singh Majhail ${ }^{1,2}$

James Douglas Rizzo ${ }^{3}$

Stephanie Joi Lee ${ }^{4}$

Mahmoud Aljurf ${ }^{5}$

Yoshiko Atsuta ${ }^{6}$

Carmem Bonfim ${ }^{7}$

Linda Jean Burns ${ }^{8}$

Naeem Chaudhri ${ }^{5}$

Stella Davies ${ }^{9}$

Shinichiro Okamoto ${ }^{10}$

Adriana Seber ${ }^{11}$

Gerard Socie ${ }^{12}$

Jeff Szer ${ }^{13}$

Maria Teresa Van Lint ${ }^{14}$

John Reid Wingard ${ }^{15}$

Andre Tichelli ${ }^{16}$

National Marrow Donor Program,

Minneapolis, MN, USA

${ }^{2}$ Center for International Blood and Marrow

Transplant Research, Minneapolis, MN, USA

${ }^{3}$ Center for International Blood and Marrow

Transplant Research, Milwaukee, WI, USA

${ }^{4}$ Fred Hutchinson Cancer Research Center, Seattle, WA, USA

${ }^{5}$ King Faisal Specialist Hospital and Research

Center, Riyadh, Saudi Arabia

${ }^{6}$ Nagoya University Graduate School of

Medicine, Nagoya, Japan

7 Universidade Federal do Paraná, Curitiba, Brazil

${ }^{8}$ University of Minnesota, Minneapolis, MN, US,

9 Cincinnati Children's Hospital, Cincinnati,

$\mathrm{OH}$, USA

${ }^{10}$ Keio University School of Medicine, Tokyo, Japan

11 Instituto de Oncologia Pediátrica - GRAACC

UNIFESP, São Paulo, SP, Brazil

${ }_{13}^{12}$ Hôpital Saint-Louis, Paris, France

Royal Melbourne Hospital, Parkville, Victoria

Australia

${ }^{14}$ San Martino Hospital, Genoa, Italy

${ }^{15}$ University of Florida College of Medicine,

Gainesville, FL, USA

${ }^{16}$ University Hospital Basel, Basel, Switzerland

Conflict-of-interest disclosure:

The authors declare no competing

financial interest

Submitted: $1 / 22 / 2012$

Accepted: 27/1/2012

Corresponding author:

Navneet S Majhail

Medical Director, National Marrow Donor

Program

3001 Broadway Street NE, Suite 100

55413-1753 Minneapolis, MN

Phone: 6128848676

nmajhail@nmdp.org

www.rbhh.org or www.scielo.br/rbhh

DOI: $10.5581 / 1516-8484.20120032$
Advances in hematopoietic cell transplantation (HCT) technology and supportive care techniques have led to improvements in long-term survival after HCT. Emerging indications for transplantation, introduction of newer graft sources (e.g. umbilical cord blood) and transplantation of older patients using less intense conditioning regimens have also contributed to an increase in the number of HCT survivors. These survivors are at risk for developing late complications secondary to pre-, periand post-transplant exposures and risk-factors. Guidelines for screening and preventive practices for HCT survivors were published in 2006. An international group of transplant experts was convened in 2011 to review contemporary literature and update the recommendations while considering the changing practice of transplantation and international applicability of these guidelines. This review provides the updated recommendations for screening and preventive practices for pediatric and adult survivors of autologous and allogeneic HCT.

Keywords: Hematopoietic cell transplantation; Allogeneic; Autologous; Late complications; Screening; Prevention

\section{Introduction}

Approximately 50,000 people undergo hematopoietic cell transplantation (HCT) worldwide each year. Advances in transplantation techniques and supportive care practices have led to progressive improvements in survival for HCT recipients. As patients survive long-term after transplantation, they are at risk for developing late complications related to pre-, peri- and post-transplant exposures. These complications can cause substantial morbidity, impair quality of life and can contribute to late mortality in HCT recipients. Several studies have shown that the life expectancy of HCT survivors is lower than expected at 10 to 30 years post-transplantation and secondary cancers, infections and organ dysfunction are common causes of late deaths in this population. ${ }^{(1-6)}$

Recognizing the need for guidance about appropriate systematic long-term followup of HCT-survivors, the Center for International Blood and Marrow Transplant Research

Notes:

For the Center for International Blood and Marrow Transplant Research (CIBMTR), American Society of Blood and Marrow Transplantation (ASBMT), European Group for Blood and Marrow Transplantation (EBMT), Asia-Pacific Blood and Marrow Transplantation Group (APBMT), Bone Marrow Transplant Society of Australia and New Zealand (BMTSANZ), East Mediterranean Blood and Marrow Transplantation Group (EMBMT) and Sociedade Brasileira de Transplante de Medula Ossea (SBTMO)

The guidelines for "Recommended screening and preventive practices for long-term survivors after hematopoietic-cell transplantation" are being co-published in the following journals: Biology of Blood and Marrow Transplantation, Bone Marrow Transplantation, Hematology/Oncology and Stem Cell Therapy and Revista Brasileira de Hematologia e Hemoterapia.

Sources of Support: The CIBMTR is supported by Public Health Service Grant/Cooperative Agreement U24-CA76518 from the National Cancer Institute (NCI), the National Heart, Lung and Blood Institute (NHLBI) and the National Institute of Allergy and Infectious Diseases (NIAID); a Grant/Cooperative Agreement 5U01HL069294 from NHLBI and NCI; a contract HHSH234200637015C with Health Resources and Services Administration (HRSA/DHHS); two grants N00014-06-10704 and N00014-08-1-0058 from the Office of Naval Research; and grants from AABB; Allos, Inc.; Amgen, Inc.; anonymous donation to the Medical College of Wisconsin; Astellas Pharma US, Inc.; Be the Match Foundation; Biogen IDEC; BioMarin Pharmaceutical, Inc.; Biovitrum AB; BloodCenter of Wisconsin; Blue Cross and Blue Shield Association; Bone Marrow Foundation; Buchanan Family Foundation; CaridianBCT; Celgene Corporation; CellGenix, GmbH; Children's Leukemia Research Association; ClinImmune Labs; CTI Clinical Trial and Consulting Services; Eisai, Inc.; Genentech, Inc.; Genzyme Corporation; Histogenetics, Inc.; HKS Medical Information Systems; Hospira, Inc.; Kirin Brewery Co., Ltd.; The Leukemia \& Lymphoma Society; Merck \& Company; The Medical College of Wisconsin; Millennium Pharmaceuticals, Inc.; Miller Pharmacal Group; Milliman USA, Inc.; Miltenyi Biotec, Inc.; National Marrow Donor Program; Nature Publishing Group; Novartis Oncology; Oncology Nursing Society; Osiris Therapeutics, Inc.; Otsuka America Pharmaceutical, Inc.; Pall Life Sciences; Pfizer Inc; Schering Corporation; Sigma-Tau Pharmaceuticals; Soligenix, Inc.; StemCyte, Inc.; StemSoft Software, Inc.; Sysmex America, Inc.; THERAKOS, Inc.; Vidacare Corporation; ViraCor Laboratories; ViroPharma, Inc.; and Wellpoint, Inc. The views expressed in this article do not reflect the official policy or position of the National Institute of Health, the Department of the Navy, the Department of Defense, or any other agency of the U.S. 
(CIBMTR), the European Group for Blood and Marrow Transplantation (EBMT), and the American Society of Blood and Marrow Transplantation (ASBMT) convened a group of experts in 2006 and provided consensus recommendations for screening and preventive practices for autologous and allogeneic HCT survivors. ${ }^{(7,8)}$ To update these previous guidelines, the international working group was reconvened in 2011 to review the prevailing literature in late effects of transplantation and to suggest revised guidelines, if applicable. To ensure international applicability, the working group included participants from the Asia-Pacific Blood and Marrow Transplantation Group (APBMT), the Bone Marrow Transplant Society of Australia and New Zealand (BMTSANZ), the East Mediterranean Blood and Marrow Transplantation Group (EMBMT) and Sociedade Brasileira de Transplante de Medula Ossea (SBTMO).

The proposed guidelines focus on risks faced by children and adults who have survived sixmonths or more following transplantation and address autologous and allogeneic HCT recipients. Since long-term HCT recipients may no longer be under the care of transplant centers and may have returned to the care of community health care providers, the guidelines are geared towards providers who routinely care for HCT recipients as well as those who do not.

The working group recognized the general lack of clinical trials focused on screening and preventive practices among HCT recipients and the need for more research in this area. Hence, many of these recommendations are not based on evidence derived from randomized or other controlled trials but are supported by retrospective studies that have identified specific complications in long-term survivors and their associated risk-factors. When such studies are not available, the guidelines are based on knowledge derived from non-transplant patients as well as on the consensus opinion of the working group participants. Taking into account the risks and potential consequences of late complications, they represent sensible practices to optimize outcomes. The recommendations should not be interpreted as mandatory for all recipients; good medical practice and judgment dictate that certain recommendations may not be applicable or may even be contraindicated in individual patients or groups of patients.

It was also recognized that the practice of HCT is continuously changing. Some examples of such changes include emerging indications for transplantation (e.g. autoimmune diseases, sickle cell disease), increased utilization of newer donor sources (e.g. umbilical cord blood and haploidentical donors), decreased use of total body irradiation (TBI) for conditioning and evaluation of novel therapies as part of HCT (e.g. post-transplant maintenance therapy in myeloma). With the advent of non-myeloablative and reduced intensity conditioning (NMA/RIC) regimens, a larger number of older patients now receive transplantation. The risks and constellation of late complications may change as newer practices in transplantation become more prevalent. Providers should be cognizant of any unique exposures and risks associated with these practices (e.g. delayed immune reconstitution in umbilical cord blood recipients) when considering a long-term followup care plan for their patients.

A broad constellation of medical issues faced by late survivors of transplantation is presented. Most of the late complications discussed here pertain particularly to allogeneic recipients. However, autologous recipients are at risk for many of the same late complications and may experience unusual toxicity or immune impairment following transplantation that places them at risk similar to allogeneic recipients (e.g. exposure to prolonged corticosteroids or other drugs that may cause prolonged lymphopenia posttransplantation). Therefore, although some of the following recommendations do not generally apply to autologous recipients, providers should remain alert to these complications in all patients.

The guidelines are summarized in Tables 1 and 2. The Appendix includes tables that highlight recommendations for post-transplant immunizations (Appendix Table A) and recommendations by selected exposures/risk-factors (TBI, chronic GVHD, pediatric recipients) (Appendix Table B). Appendix Table $\mathrm{C}$ lists other guidelines that have been referenced in this manuscript along with current links to their website. Readers can also refer to guidelines developed by the Children's Oncology Group for followup for pediatric cancer survivors, which include information on pediatric HCT recipients (www.survivorshipguidelines.org). Representative references are included in this document to guide readers who would like more information on individual topics.

The National Marrow Donor Program (NMDP) publishes a patient version of the followup guidelines (www. BeTheMatch.org/Patient); we recommend that patients use these guidelines to establish a long-term followup care plan in consultation with their health care provider based on their individual exposures and risk factors. The NMDP also makes a summary of the guidelines available for physicians, (online, mobile app, and in print at www.marrow.org/mdguidelines).

\section{Immunity and infections}

International consensus guidelines for preventing infectious complications among HCT recipients were published in 2009; these guidelines comprehensively address late infectious complications of transplantation and provide recommendations for vaccination of HCT recipients. ${ }^{(9-11)}$ Environmental risks, safe sex, water and food safety and travel safety among HCT recipients have also been covered by these guidelines. Patients who are immune compromised should be educated regarding their immune status and of the warning symptoms of infection and advised to seek early medical attention if they have symptoms. 
Table 1 - Summary recommendations for screening and prevention of late complications in long-term HCT survivors (continue)

\begin{tabular}{|c|c|c|c|c|c|}
\hline Tissues/organs & Late complications & General risk factors & Monitoring tests & $\begin{array}{l}\text { Monitoring tests and preventive } \\
\text { measures in All HCT recipients }\end{array}$ & $\begin{array}{l}\text { Monitoring tests and preventive } \\
\text { measures in special populations }\end{array}$ \\
\hline $\begin{array}{l}\text { Immune } \\
\text { system }\end{array}$ & Infections & $\begin{array}{l}\text { Donor source } \\
\text { HLA disparity } \\
\text { T-cell depletion } \\
\text { GVHD } \\
\text { Prolonged immuno- } \\
\text { suppression } \\
\text { Venous access devices }\end{array}$ & $\begin{array}{l}\text { CMV antigen or PCR } \\
\text { in patients at high risk } \\
\text { for CMV reactivation }\end{array}$ & $\begin{array}{l}\text { PCP prophylaxis for initial } 6 \text { months } \\
\text { after HCT } \\
\text { Immunizations post-transplant } \\
\text { according to published guidelines } \\
\text { Administration of antibiotics for } \\
\text { endocarditis prophylaxis according } \\
\text { to American Heart Association } \\
\text { guidelines }\end{array}$ & $\begin{array}{l}\text { Patients with cGVHD: } \\
\text { Antimicrobial prophylaxis } \\
\text { targeting encapsulated } \\
\text { organisms and PCP for the } \\
\text { duration of immunosuppressive } \\
\text { therapy } \\
\text { Patients with cGVHD: } \\
\text { Screening for CMV } \\
\text { reactivation should be based on } \\
\text { risk factors, including intensity } \\
\text { of immunosuppression. }\end{array}$ \\
\hline Ocular & $\begin{array}{l}\text { Cataracts } \\
\text { Sicca syndrome } \\
\text { Microvascular } \\
\text { retinopathye }\end{array}$ & $\begin{array}{l}\text { TBI/radiation exposure to } \\
\text { head and neck } \\
\text { Corticosteroids } \\
\text { GVHD }\end{array}$ & $\begin{array}{l}\text { Ophthalmologic } \\
\text { exam }\end{array}$ & $\begin{array}{l}\text { Routine clinical evaluation at } \\
6 \text { months and } 1 \text { year after HCT } \\
\text { and at least yearly thereafter } \\
\text { Ophthalmologic examination with } \\
\text { measurement of visual acuity and } \\
\text { fundus examination at } 1 \text { year after } \\
\text { HCT, subsequent evaluation based } \\
\text { on findings and risk-factors } \\
\text { Prompt ophthalmologic examination } \\
\text { in patients with visual symptoms }\end{array}$ & $\begin{array}{l}\text { Patients with cGVHD: } \\
\text { Routine clinical evaluation, and } \\
\text { if indicated, ophthalmologic } \\
\text { examination more frequently }\end{array}$ \\
\hline Oral & $\begin{array}{l}\text { Sicca syndrome } \\
\text { Caries }\end{array}$ & $\begin{array}{l}\text { GVHD } \\
\text { TBI/radiation exposure to } \\
\text { head and neck }\end{array}$ & $\begin{array}{l}\text { Dental } \\
\text { assessment }\end{array}$ & $\begin{array}{l}\text { Education about preventive oral } \\
\text { health practices } \\
\text { Clinical oral assessment at } 6 \text { months } \\
\text { and } 1 \text { year after HCT and at least yearly } \\
\text { thereafter with particular attention to } \\
\text { intra-oral malignancy evaluation } \\
\text { Dental assessment at } 1 \text { year after HCT } \\
\text { and then at least yearly thereafter }\end{array}$ & $\begin{array}{l}\text { Pediatric recipients: } \\
\text { Yearly assessment of } \\
\text { teeth development } \\
\text { Patients with cGVHD: } \\
\text { Consider more frequent oral } \\
\text { and dental assesments with } \\
\text { particular attention to intra-oral } \\
\text { malignancy evaluation }\end{array}$ \\
\hline Respiratory & $\begin{array}{l}\text { Idiopathic } \\
\text { pneumonia syndrome } \\
\text { Bronchiolitis } \\
\text { obliterans syndrome } \\
\text { Cryptogenic } \\
\text { organizing pneumonia } \\
\text { Sino-pulmonary } \\
\text { infections }\end{array}$ & $\begin{array}{l}\text { TBI/radiation exposure to } \\
\text { chest } \\
\text { GVHD } \\
\text { Infectious agents } \\
\text { Allogeneic HCT } \\
\text { Busulfan exposure }\end{array}$ & $\begin{array}{l}\text { PFT's } \\
\text { Radiologic studies } \\
\text { (e.g. chest X-ray, } \\
\text { CT scan) }\end{array}$ & $\begin{array}{l}\text { Routine clinical evaluation at } \\
6 \text { months and } 1 \text { year after HCT and } \\
\text { at least yearly thereafter } \\
\text { Assessment of tobacco use and } \\
\text { couselling against smoking } \\
\text { PFT's and focused radiologic - assessment } \\
\text { for allogeneic HCT recipients with } \\
\text { symptoms or signs of lung compromise }\end{array}$ & $\begin{array}{l}\text { Patients with cGVHD: } \\
\text { Some experts recommend } \\
\text { earlier and more frequent } \\
\text { clinical evaluation and PFT's }\end{array}$ \\
\hline $\begin{array}{l}\text { Cardiac and } \\
\text { vascular }\end{array}$ & $\begin{array}{l}\text { Cardiomyopathy } \\
\text { Congestive heart } \\
\text { failure } \\
\text { Arrhythmias } \\
\text { Valvular anomaly } \\
\text { Coronary artery } \\
\text { disease } \\
\text { Cerebrovascular } \\
\text { disease } \\
\text { Peripheral arterial } \\
\text { disease }\end{array}$ & $\begin{array}{l}\text { Anthracycline exposure } \\
\text { TBI/radiation exposure to } \\
\text { neck or chest } \\
\text { Older age at HCT } \\
\text { Allogeneic HCT } \\
\text { Cardiovascular risk-factors } \\
\text { before/after HCT } \\
\text { Chronic kidney disease } \\
\text { Metabolic syndrome }\end{array}$ & $\begin{array}{l}\text { Cumulative dose of } \\
\text { anthracyclines } \\
\text { Echocardiogram with } \\
\text { ventricular function, } \\
\text { ECG in patients at } \\
\text { risk and in } \\
\text { symptomatic patients } \\
\text { Fasting lipid profile } \\
\text { (including HDL-C, } \\
\text { LDL-C and } \\
\text { triglycerides) } \\
\text { Fasting blood sugar }\end{array}$ & \multicolumn{2}{|l|}{$\begin{array}{l}\text { Routine clinical assessment of cardiovascular } \\
\text { risk factors as per general health maintenance } \\
\text { at } 1 \text { year and at least yearly thereafter } \\
\text { Education and counseling on "heart" healthy } \\
\text { lifestyle (regular exercise, healthy weight, no } \\
\text { smoking, dietary counseling) } \\
\text { Early treatment of cardiovascular risk factors } \\
\text { such as diabetes, hypertension and } \\
\text { dyslipidemia } \\
\text { Administration of antibiotics for endocarditis } \\
\text { prophylaxis according to American Heart } \\
\text { Association guidelines }\end{array}$} \\
\hline Liver & $\begin{array}{l}\text { GVHD } \\
\text { Hepatitis B } \\
\text { Hepatitis C } \\
\text { Iron overload }\end{array}$ & $\begin{array}{l}\text { Cumulative transfusion } \\
\text { exposure } \\
\text { Risk factors for viral hepatitis } \\
\text { transmission }\end{array}$ & $\begin{array}{l}\text { LFT's } \\
\text { Liver biopsy } \\
\text { Serum ferritin } \\
\text { Imaging for iron } \\
\text { overload (MRI or } \\
\text { SQUID) }\end{array}$ & \multicolumn{2}{|c|}{$\begin{array}{l}\text { LFT's every } 3-6 \text { months in the first year, then } \\
\text { individualized, but at least yearly thereafter } \\
\text { Monitor viral load by PCR for patients } \\
\text { with known hepatitis B or C, with liver and } \\
\text { infectious disease specialist consultation } \\
\text { Consider liver biopsy at } 8-10 \text { years after } \\
\text { HCT to assess cirrhosis in patients with } \\
\text { chronic HCV infection } \\
\text { Serum ferritin at } 1 \text { year after HCT in patients } \\
\text { who have received RBC transfusions; consider } \\
\text { liver biopsy or imaging study for abnormal } \\
\text { results based on magnitude of elevation and } \\
\text { clinical context; subsequent monitoring is } \\
\text { suggested for patients with elevated LFT's, } \\
\text { continued RBC transfusions, or presence of } \\
\text { HCV infection }\end{array}$} \\
\hline
\end{tabular}


Table 1 (continuation)

\begin{tabular}{|c|c|c|c|c|c|}
\hline Tissues/organs & Late complications & General risk factors & Monitoring tests & $\begin{array}{l}\text { Monitoring tests and preventive } \\
\text { measures in All HCT recipients }\end{array}$ & $\begin{array}{l}\text { Monitoring tests and preventive } \\
\text { measures in special populations }\end{array}$ \\
\hline $\begin{array}{l}\text { Renal and } \\
\text { genitourinary }\end{array}$ & $\begin{array}{l}\text { Chronic kidney disease } \\
\text { Bladder dysfunction } \\
\text { Urinary tract infections }\end{array}$ & $\begin{array}{l}\text { TBI } \\
\text { Drug exposure } \\
\text { (e.g. calcineurin inhibitors, } \\
\text { amphotericin, } \\
\text { aminoglycosides) } \\
\text { CMV } \\
\text { Hemorrhagic cystitis }\end{array}$ & $\begin{array}{l}\text { Urine protein } \\
\text { Serum creatinine } \\
\text { BUN }\end{array}$ & $\begin{array}{l}\text { Blood pressure assessment at } \\
\text { every clinic visit, with aggressive } \\
\text { hypertension management } \\
\text { Assess renal function with } \\
\text { BUN, creatinine and urine } \\
\text { protein at } 6 \text { months, } \\
1 \text { year and at least yearly thereafter } \\
\text { Consider further workup (kidney } \\
\text { biopsy or renal ultrasound) for for } \\
\text { further workup of renal } \\
\text { dysfunction as clinically indicated }\end{array}$ & \\
\hline
\end{tabular}

$\begin{array}{lll}\text { Muscle and } & \text { Myopathy } & \text { Corticosteroids } \\ \text { connective } & \text { Fascitis/scleroderma } & \text { GVHD }\end{array}$

tissue Polymyositis
Evaluate ability to stand from a sitting position Clinical evaluation of joint range of motion
Follow general population guidelines for physical activity Frequent clinical evaluation for myopathy in patients on corticosteroids

\begin{tabular}{|c|c|c|c|c|}
\hline Skeletal & $\begin{array}{l}\text { Osteopenia/ } \\
\text { osteoporosis } \\
\text { Avascular necrosis }\end{array}$ & $\begin{array}{l}\text { Inactivity } \\
\text { TBI } \\
\text { Corticosteroids } \\
\text { GVHD } \\
\text { Hypogonadism } \\
\text { Allogeneic HCT }\end{array}$ & $\begin{array}{l}\text { Dual photon densitometry } \\
\text { MRI to evaluate } \\
\text { patients with joint } \\
\text { symptoms }\end{array}$ & $\begin{array}{l}\text { Dual photon densitometry at } \\
1 \text { year for adult women, all } \\
\text { allogeneic HCT recipients and } \\
\text { patients who are at high risk for } \\
\text { bone loss; subsequent testing } \\
\text { determined by defects or to } \\
\text { assess response to therapy } \\
\text { Physical activity, vitamin D and } \\
\text { calcium supplementation to } \\
\text { prevent loss of bone density }\end{array}$ \\
\hline $\begin{array}{l}\text { Nervous } \\
\text { system }\end{array}$ & $\begin{array}{l}\text { Leukoencephalopathy } \\
\text { Late infections } \\
\text { Neuropsychological } \\
\text { and cognitive deficits } \\
\text { Calcineurin neurotoxicity } \\
\text { Peripheral neuropathy }\end{array}$ & $\begin{array}{l}\text { TBL/radiation exposure } \\
\text { to head } \\
\text { GVHD } \\
\text { Exposure to fludarabine } \\
\text { Intrathecal chemotherapy }\end{array}$ & $\begin{array}{l}\text { Clinical evaluation } \\
\text { for symptoms and signs } \\
\text { of neurologic dysfunction } \\
\text { at } 1 \text { year and yearly } \\
\text { thereafter } \\
\text { Diagnostic testing } \\
\text { (e.g., radiographs, } \\
\text { nerve conduction studies) } \\
\text { for those with symptoms } \\
\text { or signs }\end{array}$ & $\begin{array}{l}\text { Pediatric recipients: Annual } \\
\text { assessment for congnitive } \\
\text { development milestones }\end{array}$ \\
\hline Endocrine & $\begin{array}{l}\text { Hypothyroidism } \\
\text { Hypoadrenalism } \\
\text { Hypogonadism } \\
\text { Growth retardation }\end{array}$ & $\begin{array}{l}\text { TBL/radiation exposure } \\
\text { (e.g. head and neck, CNS) } \\
\text { Corticosteroids } \\
\text { Young age at HCT } \\
\text { Chemotherapy exposure }\end{array}$ & $\begin{array}{l}\text { Thyroid function tests } \\
\text { FSH, LH, testosterone } \\
\text { Growth velocity } \\
\text { in children }\end{array}$ & $\begin{array}{l}\text { Thyroid function testing yearly } \\
\text { post-HCT, or if relevant } \\
\text { symptoms develop } \\
\text { Clinical and endocrinologic } \\
\text { gonadal assessment for } \\
\text { post-pubertal women at } 1 \text { year, } \\
\text { subsequent followup based } \\
\text { on menopausal status } \\
\text { Gonadal function in men, } \\
\text { including FSH, LH and } \\
\text { testosterone, should be assessed } \\
\text { as warranted by symptoms }\end{array}$ \\
\hline
\end{tabular}

Patients with cGVHD:

Physical therapy consultation in patients with prolonged corticosteroid exposure, fascitis or scleroderma Patients with cGVHD:

Frequent clinical evaluation by manual muscle tests or by assessing ability to go from sitting to standing position for patients on prolonged corticosteroids

Patients with cGVHD: Consider dual photon densitometry at an earlier date in patients with prolonged corticosteroid or calcineurin inhibitor exposure
Pediatric recipients: Clinical and endocrinologic gonadal assessment for pre-pubertal boys and girls within 1 year of transplant, with further followup as determined in consultation with a pediatric endocrinologist

Pediatric recipients: Monitor growth velocity in children annually; assessment of thyroid, and growth hormone function if clinically indicated Patients with cGVHD: Slow terminal tapering of corticosteroids for those with prolonged exposuer

Patients with cGVHD:

Consider stress doses of corticosteroids during acute illness for patients who have received chronic corticosteroids 


\begin{tabular}{|c|c|c|c|c|c|}
\hline Tissues/organs & Late complications & General risk factors & Monitoring tests & $\begin{array}{l}\text { Monitoring tests and preventive } \\
\text { measures in All HCT recipients }\end{array}$ & $\begin{array}{l}\text { Monitoring tests and preventive } \\
\text { measures in special populations }\end{array}$ \\
\hline $\begin{array}{l}\text { Muco- } \\
\text { cutaneous }\end{array}$ & $\begin{array}{l}\text { Cutaneous } \\
\text { sclerosis } \\
\text { Genital GVHD }\end{array}$ & $\begin{array}{l}\text { GVHD } \\
\text { TBI/radiation } \\
\text { exposure to pelvis }\end{array}$ & Pelvic exam & $\begin{array}{l}\text { Counsel patients to perform } \\
\text { routine self exam of skin and } \\
\text { avoid excessive exposure to } \\
\text { sunlight without adequate protection } \\
\text { Annual gynecologic exam in } \\
\text { women to detect early involvement } \\
\text { of vaginal mucosa by GVHD }\end{array}$ & $\begin{array}{l}\text { Patients with cGVHD and } \\
\text { TBI recipients: Consider more } \\
\text { frequent gynecologic } \\
\text { evaluation based on clinical } \\
\text { symptoms }\end{array}$ \\
\hline $\begin{array}{l}\text { Second } \\
\text { cancers }\end{array}$ & $\begin{array}{l}\text { Solid tumors } \\
\text { Hematologic } \\
\text { malignancies } \\
\text { PTLD }\end{array}$ & $\begin{array}{l}\text { GVHD } \\
\text { TBI/radiation exposure } \\
\text { T-cell depletion } \\
\text { Exposure to alkylating } \\
\text { agents or etoposide }\end{array}$ & $\begin{array}{l}\text { Mammogram } \\
\text { Screening for colon } \\
\text { cancer (e.g. colonoscopy, } \\
\text { sigmoidoscopy, fecal } \\
\text { occult blood testing) } \\
\text { Pap smear }\end{array}$ & $\begin{array}{l}\text { Counsel patients about risks of } \\
\text { secondary malignancies annually and } \\
\text { encourage them to perform self exam } \\
\text { (e.g. skin, testicles/genitalia) } \\
\text { Counsel patients to avoid high risk } \\
\text { behaviors (e.g. smoking) } \\
\text { Follow general population } \\
\text { recommendations for cancer } \\
\text { screening }\end{array}$ & $\begin{array}{l}\text { Patients with cGVHD: Clinical } \\
\text { and dental evaluation with } \\
\text { particular attention towards } \\
\text { oral and pharyngeal cancer } \\
\text { TBI and chest irradiation } \\
\text { recipients: Screening } \\
\text { mammography in women } \\
\text { starting at age } 25 \text { or } 8 \text { years } \\
\text { after radiation exposure, } \\
\text { which ever occurs later but } \\
\text { no later than age } 40\end{array}$ \\
\hline $\begin{array}{l}\text { Psychosocial } \\
\text { and sexual }\end{array}$ & $\begin{array}{l}\text { Depression } \\
\text { Anxiety } \\
\text { Fatigue } \\
\text { Sexual } \\
\text { dysfunction }\end{array}$ & $\begin{array}{l}\text { Prior psychiatric } \\
\text { morbidity } \\
\text { Hypogonadism }\end{array}$ & $\begin{array}{l}\text { Psychological } \\
\text { evaluation }\end{array}$ & $\begin{array}{l}\text { Clinical assessment throughout } \\
\text { recovery period, at } 6 \text { months, } \\
1 \text { year and annually thereafter, } \\
\text { with mental health professional } \\
\text { counseling recommended for } \\
\text { those with recognized deficits } \\
\text { Encouragement of robust support } \\
\text { networks } \\
\text { Regularly assess level of spousal/ } \\
\text { caregiver psychological } \\
\text { adjustment and } \\
\text { family functioning } \\
\text { Query adults about sexual function } \\
\text { at } 6 \text { months, } 1 \text { year and at least } \\
\text { annually thereafter }\end{array}$ & \\
\hline Fertility & Infertility & $\begin{array}{l}\text { TBI/radiation exposure } \\
\text { Chemotherapy exposure }\end{array}$ & FSH, LH levels & $\begin{array}{l}\text { Consider referral to appropriate specialists } \\
\text { for patients who are contemplating a } \\
\text { pregnancy or are having difficulty conceiving } \\
\text { Counsel sexually active patients in the } \\
\text { reproductive age group about birth } \\
\text { control post-HCT }\end{array}$ & \\
\hline General health & & & & $\begin{array}{l}\text { Recommended screening as } \\
\text { per general population (see text) }\end{array}$ & \\
\hline
\end{tabular}

HCT indicates hematopoietic cell transplantation; cGVHD, chronic graft-versus-host disease; CMV, cytomegalovirus; PCR, polymerase chain reaction; PCP, Pneumocystis pneumonia; TBI, total body irradiation; PFT's, pulmonary function tests; CT, computed tomography; ECG, electrocardiogram; LFT's, liver function tests; MRI; magnetic resonance imaging; SQUID, superconducting quantum interference device; HCV, hepatitis C; RBC, red blood cell; BUN, blood urea nitrogen; CNS, central nervous system; FSH, follicle stimulating hormone; LH, luteinizing hormone; PTLD, post-transplant lymphoproliferative disorder

Infectious complications are frequent in the period soon after HCT because of cytopenias, immune ablation and/or immunosuppression. Immune reconstitution occurs gradually over time (generally 12-18 months) and is slower for allogeneic recipients, particularly those receiving umbilical cord blood, HLA-mismatched or T-cell depleted grafts and in survivors with graft-versus-host disease (GVHD) or those who have received prolonged immunosuppression. ${ }^{(12)}$ T-helper lymphocyte (CD4) counts and CD4/CD8 ratios are good markers of immune reconstitution and some experts use these assessments as surrogate markers of the completeness of immune reconstitution to guide duration of viral or other infection prophylaxis after HCT.

Bacterial, fungal, and viral infections may occur months or years after transplantation in patients with delayed immune reconstitution. Although infectious risk is highest in the first 1-2 years after transplantation, an increased risk of infection may continue long-term for some recipients of allogeneic transplants, such as patients with chronic GVHD requiring extended immunosuppressive therapy. In patients with chronic GVHD, opsonization is impaired, and encapsulated bacteria ( $N$. meningitides, $H$. influenzae, and S. pneumonia) may cause rapidly progressive and life-threatening infection. Furthermore, patients may have undergone splenectomy for the treatment of their underlying disease or may be functionally asplenic secondary to GVHD or splenic irradiation. Although patients with asplenia are at increased risk of infections, recommendations regarding antibiotic prophylaxis are inconsistent. Patients with combined risk of asplenia and immunosuppression for GVHD should receive antibiotic 
Table 2 - Abbreviated summary recommendations for screening and prevention of late complications in long-term HCT survivors organized by time after transplantation

\begin{tabular}{|c|c|c|c|}
\hline Recommended Screening/Prevention & $6 \mathrm{mo}$ & $1 \mathrm{yr}$ & Annually \\
\hline \multicolumn{4}{|l|}{ Immunity } \\
\hline Encapsulated organism prophylaxi & 2 & 2 & 2 \\
\hline PCP prophylaxis & 1 & 2 & 2 \\
\hline CMV testing & 2 & 2 & 2 \\
\hline Immunizations & 1 & 1 & 1 \\
\hline \multicolumn{4}{|l|}{ Ocular } \\
\hline Ocular clinical symptom evaluation & 1 & 1 & 1 \\
\hline Ocular fundus exam & + & 1 & + \\
\hline Oral complications & 1 & 1 & 1 \\
\hline $\begin{array}{l}\text { Clinical assessment } \\
\text { Dental assessment }\end{array}$ & + & 1 & 1 \\
\hline \multicolumn{4}{|l|}{ Respiratory } \\
\hline Clinical pulmonary assessment & 1 & 1 & 1 \\
\hline Smoking tobacco avoidance & 1 & 1 & 1 \\
\hline Pulmonary function testing & + & + & + \\
\hline Chest radiography & + & + & + \\
\hline \multicolumn{4}{|l|}{ Cardiac and vascular } \\
\hline Cardiovascular risk-factor assessment & + & 1 & 1 \\
\hline \multicolumn{4}{|l|}{ Liver } \\
\hline Liver function testing & 1 & 1 & + \\
\hline Serum ferritin testing & & 1 & + \\
\hline \multicolumn{4}{|l|}{ Kidney } \\
\hline Blood pressure screening & 1 & 1 & 1 \\
\hline Urine protein screening & 1 & 1 & 1 \\
\hline BUN/creatinine testing & 1 & 1 & 1 \\
\hline \multicolumn{4}{|l|}{ Muscle and connective tissue } \\
\hline Evaluation for muscle weakness & 2 & 2 & 2 \\
\hline Physical activity counseling & 1 & 1 & 1 \\
\hline \multicolumn{4}{|l|}{ Skeletal } \\
\hline $\begin{array}{l}\text { Bone density testing (adult women, all allogeneic } \\
\text { transplant recipients and patients at high risk for } \\
\text { bone loss) }\end{array}$ & & 1 & + \\
\hline \multicolumn{4}{|l|}{ Nervous system } \\
\hline Neurologic clinical evaluation & + & 1 & 1 \\
\hline Evaluate for cognitive development & & 1 & 1 \\
\hline \multicolumn{4}{|l|}{ Endocrine } \\
\hline Thyroid function testing & & 1 & 1 \\
\hline Growth velocity in children & & 1 & 1 \\
\hline $\begin{array}{l}\text { Gonadal function assessment (prepubertal men } \\
\text { and women) }\end{array}$ & 1 & 1 & 1 \\
\hline $\begin{array}{l}\text { Gonadal function assessment (postpubertal } \\
\text { women) }\end{array}$ & & 1 & + \\
\hline Gonadal function assessment (postpubertal men) & & + & + \\
\hline \multicolumn{4}{|l|}{ Muco-cutaneous } \\
\hline Skin self-exam and sun exposure counseling & 1 & 1 & 1 \\
\hline Gynecologic exam in women & + & 1 & 1 \\
\hline \multicolumn{4}{|l|}{ Second cancers } \\
\hline Second cancer vigilance counseling & & 1 & 1 \\
\hline Screening for second cancers & & 1 & 1 \\
\hline \multicolumn{4}{|l|}{ Psychosocial } \\
\hline Psychosocial/QOL clinical assessment & 1 & 1 & 1 \\
\hline Sexual function assessment & 1 & 1 & 1 \\
\hline
\end{tabular}

$1=$ recommended for all transplant recipients

$2=$ recommended for any patient with ongoing chronic GVHD or

immunosuppression

$+=$ reassessment recommended for abnormal testing in a previous time period or for new signs/symptoms prophylaxis as recommended below. Otherwise patients with asplenia should, at a minimum, be warned regarding the need for prompt medical attention for febrile illnesses.

Aspergillus infection of the lungs or sinuses is the most commonly described late fungal infection although Candida and Mucor species are late pathogens seen infrequently. Late-onset cytomegalovirus (CMV) reactivation and infection has been reported more frequently in recent years with the increasing use of prophylactic or preemptive antiviral drugs in the early post-HCT period. Late CMV infections are most commonly seen in patients treated for early CMV infection or in those with chronic GVHD or late immune manipulation (e.g. donor lymphocyte infusion recipients). Varicella zoster virus (VZV) infection frequently occurs in the first year after transplantation, especially in patients with chronic GVHD. In patients receiving prophylaxis against herpes virus infections, VZV reactivation is most commonly seen in the 2-3 months after cessation of prophylaxis. Acyclovir prophylaxis is recommended for 1-year post-transplantation for both autologous and allogeneic recipients at risk for VZV disease; prophylaxis may be continued beyond 1-year among patients who have chronic GVHD or require systemic immune-suppression. Recurrent herpes simplex virus infections can occasionally occur in patients with chronic GVHD.

Although Pneumocystis jirovecii (previously Pneumocystis carinii) pneumonia (PCP) generally occurs during the first six months after HCT, patients are at risk for as long as immunosuppressive therapy is given for chronic GVHD. Autologous HCT recipients are also at risk of PCP, particularly during the first six months; the risk may be substantial if there has been prolonged corticosteroid exposure before or after transplantation and in patients who have received intensive conditioning.

Sinusitis is an occasional complication, especially after allogeneic HCT, and is more frequent in patients with low immunoglobulin levels. Sinus pathogens are rarely identified because invasive diagnostic procedures are not frequently performed. Exposure to calcineurin inhibitors that can induce mucosal hypertrophy and mucosal involvement by chronic GVHD can increase the risk of secondary sinus infections with bacteria or molds.

Supplemental intravenous immune globulin (IVIg) is sometimes recommended for patients with severe infections and $\mathrm{IgG}$ levels below $400 \mathrm{mg} / \mathrm{dL}(4 \mathrm{~g} / \mathrm{L})$ and infusions are continued until infection has abated. ${ }^{(9,10)}$ The use of prophylactic IVIg in HCT patients in the absence of infection remains controversial.

Transplant recipients who reside in certain geographic areas may be susceptible to locally prevalent infections (e.g., tuberculosis, malaria, Chagas disease, leishmaniasis). Health care providers taking care of such patients should be aware of guidelines for the prevention and management of such infections. ${ }^{(10,13,14)}$ 


\section{Recommendations}

- Patients with chronic GVHD should receive antibiotic prophylaxis targeting encapsulated organisms given for at least as long as immunosuppressive therapy is administered.

- Antiviral and antifungal prophylaxis should be considered in patients at high risk for viral and fungal infections (e.g., patients with chronic GVHD) according to published guidelines. ${ }^{(9,10)}$ Screening for CMV reactivation should be based on risk factors, including intensity of immunosuppression.

- Administration of prophylactic antibiotics for oral procedures should follow the American Heart Association guidelines for endocarditis prophylaxis. ${ }^{(15)}$ Some experts recommend antibiotic prophylaxis before dental care in patients on immunosuppressive therapy for chronic GVHD and in patients with indwelling central venous catheters.

- Allogeneic HCT recipients should receive PCP prophylaxis from engraftment until at least six months after transplantation or as long as immunosuppressive therapy is given (e.g., for the treatment or prevention of chronic GVHD). PCP prophylaxis for three to six months posttransplantation should be considered for autologous HCT recipients with substantial immunosuppression (e.g. patients with lymphoma, leukemia or myeloma, especially when pre-transplant treatments or conditioning regimens have included purine analogues or high dose corticosteroids).

- Immunization with inactivated vaccines for all patients according to published guidelines (Appendix Table A). ${ }^{(9-11)}$ Since patients with chronic GVHD can mount responses to vaccines and are at risk for infections, postponing vaccination in patients with GVHD is not recommended with the exception of live vaccines. When vaccinating patients with active GVHD, it may be prudent to measure specific antibody levels before and after vaccination, to determine their level of protection and need for booster immunizations.

\section{Ocular complications}

There are three main ocular late effects after HCT. Anterior segment ocular complications of keratoconjunctivitis sicca syndrome and cataracts are well described. Ischemic microvascular retinopathy is a posterior segment complication that is being increasingly recognized and appears to be related to radiation exposure.

Ocular sicca syndrome is usually part of a more general sicca syndrome with xerostomia, vaginitis, and dryness of skin and is associated with chronic GVHD. ${ }^{(16)}$ Ocular manifestations include reduced tear flow, keratoconjunctivitis sicca, sterile conjunctivitis, corneal epithelial defects, and corneal ulceration. Symptoms include burning, irritation, pain, foreign body sensation, blurred vision, photophobia, and paradoxically, excessive tearing. The diagnosis of keratoconjunctivitis sicca is made by the presence of appropriate symptoms, evidence of decreased tear production on Schirmer's test, and clinical signs of keratitis. In all cases, infectious keratitis must be ruled out. The incidence is approximately $40-60 \%$ in patients with chronic GVHD. ${ }^{(17)}$ Artificial tears can provide symptomatic treatment of dry eye. Information regarding frequency of use of artificial tear drops can indicate severity of dry eye syndrome. Treatment includes systemic treatment of chronic GVHD and topical treatment to increase lubrication, control evaporation or drainage, and decrease ocular surface inflammation. ${ }^{(18)}$ Temporary or permanent occlusion of the tear-duct puncta for drainage control may provide benefit. In general, contact lens usage is discouraged in patients with keratoconjunctivitis sicca because of an increased risk of abrasion: however, some lenses such as scleral lenses may be beneficial in severe cases to control evaporation. Such an approach should occur only with the close supervision of an ophthalmologist. Topical corticosteroids or calcineurin inhibitors may improve symptoms but can cause sight-threatening complications when inappropriately used in herpes simplex virus or bacterial keratitis. Ocular surface inflammation may be decreased with autologous serum, but this treatment is available in a limited number of centers.

Cataract formation occurs frequently after TBI exposure. After myeloablative single-dose TBI, almost all patients develop cataracts within three to four years. Fractionation of TBI delays onset and reduces the incidence of cataract to $40-70 \%$ at ten years post-transplant. ${ }^{(19,20)}$ In patients conditioned without TBI, the probability of cataract formation at 10 years is $5-20 \% .^{(20,21)}$ Other risk factors for cataract formation after HCT are older age, use of corticosteroids, and allogeneic compared to autologous transplantation. Approximately $45 \%$ of recipients treated with corticosteroids for a prolonged period of time develop cataracts at 10 years. In the near future, the overall cumulative incidence of cataracts after HCT is expected to decrease as fewer patients receive TBI based conditioning. Cataracts are effectively treated surgically. Cataract extraction can be performed safely even when ocular sicca is present. Surgery is indicated if vision is impaired and the impairment is interfering with daily life.

Ischemic microvascular retinopathy presents with cotton-wool spots and optic-disc edema. Retinopathy is observed almost exclusively after allogeneic transplantation, particularly in patients conditioned with TBI and in patients receiving cyclosporine for GVHD prophylaxis. In most cases, retinal lesions resolve with withdrawal or reduction of immunosuppressive therapy, even in cases where visual acuity is decreased. Other ocular complications in the posterior segment include hemorrhage, optic disc edema, and infectious retinitis (e.g., from herpes viruses including CMV, toxoplasma, and fungi). 


\section{Recommendations}

- Routine clinical evaluation of visual history and symptoms, with attention to sicca syndrome, is recommended at 6 months, 1 year and yearly thereafter for all HCT recipients.

- Referral to an expert in ophthalmology for routine ocular examination with measurement of visual acuity and fundus examination at 1 year after transplant is recommended for all HCT recipients. Patients with chronic GVHD may be referred for ophthalmologic exam sooner than 1 year posttransplant. Subsequent frequency of routine screening should be individualized according to recognized defects, ocular symptoms or the presence of chronic GVHD.

- Patients experiencing visual symptoms should undergo ocular examination immediately.

\section{Oral complications}

Late complications involving the oral cavity are common after HCT. The most important risk factors for oral late effects are oral chronic GVHD, the use and dose of irradiation to head and neck region, underlying diagnosis of Fanconi's anemia and the age of the patient at HCT. Pre-transplant evaluation should include clinical assessment of oral health status to serve as a baseline for monitoring post-transplant oral complications.

The mouth is one of the most frequently affected organs in chronic GVHD. ${ }^{(22,23)}$ The oral changes involving the oral mucosa, salivary glands, oral and lingual muscles, taste buds and gingiva may completely regress, but some long term sequela may continue despite the resolution of chronic GVHD. Patients often report oral pain, dryness, odynophagia, dysphagia and sensitivity (irritation from normally tolerated spices, foods, liquids or flavors) that may limit oral intake. The presence of lichen planus, hyperkeratotic plaques and restriction of mouth opening by peri-oral fasciitis or skin sclerosis are diagnostic signs of oral GVHD. Patients may also have mucosal erythema, atrophy, oral dryness, mucoceles (due to inflammation and obstruction of the salivary gland ducts), pseudomembranes and ulcers. Salivary gland dysfunction and xerostomia increase the risk of dental caries, periodontal disease and oral cancer. ${ }^{(22,24)}$ Patients with GVHD can be treated with topical oral steroids, systemic treatments for GVHD, and supportive care for xerostomia symptoms as outlined below.

Even in patients who have never had GVHD, some degree of salivary gland hypofunction may persist for prolonged periods of time after receiving chemotherapy, and especially after local irradiation. Oral dryness is also a side effect of commonly used medications (e.g. antidepressants, anti-histamines, diuretics, muscle relaxants and some analgesics). Medication lists should be reviewed to identify and eliminate any drugs that can cause or exacerbate xerostomia. Depending on the severity of xerostomia, patients may complain of oral sensitivity, abnormal taste and may feel a constant sore throat, or have problems speaking and swallowing. The decrease in salivation predisposes patients to dental decay, oral infections (e.g. herpes simplex and oral candidiasis), mechanical and epithelial injuries, and impairs re-mineralization of teeth. Xerostomia can be difficult to manage. Symptom relief can be achieved with artificial saliva and oral rinses; sugar-free candies or gum can stimulate the saliva flow. Sialogogues (e.g. pilocarpine, cevimeline) may be tried in adults. Frequent sipping of water may help decrease symptoms, and especially help chewing and swallowing food. Patients with xerostomia should receive meticulous oral hygiene, undertake preventive measures for dental and periodontal disease, and aggressive treatment of oral infections. Further trauma to the oral mucosa should be avoided and mouth-guards may be used, if necessary. Oral piercing should be avoided.

Squamous cell oral cancer can arise from the buccal mucosa, salivary glands, gingiva, lip or tongue (see section on Secondary cancers). ${ }^{(24-26)}$ Patients with a history of oral chronic GVHD and patients with Fanconi's anemia are particularly at risk and must be carefully screened throughout their lives. Frequent self and professional oral examination is the mainstay for early diagnosis of oral cancer. Patients should be vigilant for and report lesions that do not heal, leukoplakia, localized pain and changes in color or texture of the mucosa. Patients with Fanconi's anemia should be examined every six months and oral examination should be part of the standard annual examination of all other HCT patients.

Children undergoing HCT may have damage to the enamel layer and the teeth may have discolored patches or stain easily. Depending on the child's age, permanent teeth may start developing again within a few months of transplantation. Normal dental development may be altered in $50 \%-80 \%$ of children due to prior therapies or conditioning regimen exposure. ${ }^{(27)}$ Tooth agenesis, hypodontia, microdontia of the crowns of erupted permanent teeth, narrowing of the pulp canal, thinning and tapering of the roots of erupted permanent molars or incisors, delayed eruption and primary tooth retention have been described and may jeopardize occlusal development. After irradiation, underdevelopment of the mandible and anomalies in the mandibular joint may also occur. Young age at HCT and exposure to TBI are important risk factors for problems with dental development.

Among HCT recipients who require dental procedures, the American Heart Association recommendations for antimicrobial prophylaxis against endocarditis should be followed (see section on "Immunity and infections"). ${ }^{(15)}$

\section{Recommendations}

- All HCT recipients should be educated about preventive oral health and routine dental maintenance. Patients should also be counseled to avoid smoking and 
chewing tobacco, decrease regular intake of sugar containing beverages, and avoid intraoral piercing.

- Clinical oral evaluations should be performed at six months, one year and yearly thereafter. More frequent evaluations may be needed in patients at high-risk of oral complications (e.g. chronic GVHD, exposure to TBI). Monitoring of oral complications post-transplantation is facilitated by thorough pre-HCT baseline oral assessment.

- Patients at high-risk for squamous cell cancers of the oral cavity (e.g., oral chronic GVHD, Fanconi's anemia) should undergo clinical oral evaluations every six months and should be educated to maintain meticulous oral hygiene and taught oral self-inspection.

- All HCT recipients should receive a thorough evaluation by a dentist or oral medicine specialist at one year after HCT and yearly thereafter. More frequent dental consultations may be considered in patients with oral GVHD or Fanconi's anemia. At each visit it is important to check for a history of xerostomia and high-risk habits, to perform a through oral, head and neck and dental exam. Appropriate dental and radiologic assessment for tooth development should be performed in children.

\section{Respiratory complications}

Late pulmonary complications among HCT recipients include idiopathic pneumonia syndrome, bronchiolitis obliterans syndrome (BOS), cryptogenic organizing pneumonia (COP) and sino-pulmonary infections. ${ }^{(28)}$ Allogeneic HCT recipients have higher risks than autologous HCT recipients. Predisposing factors can include infections, extent and type of pre-transplant and conditioning regimen chemotherapy and radiation exposure, and GVHD. Pulmonary complications can be associated with significant morbidity and mortality.

Idiopathic pneumonia syndrome, also known as interstitial pneumonitis, more commonly presents in the early post-transplant period. However, it can occur in long-term survivors and can lead to late respiratory impairment. Predisposing factors include allogeneic HCT, exposure to high dose TBI, and GVHD. Immune compromise delays recovery from infection, allowing greater damage to the lung interstitium. Certain chemotherapeutic agents (e.g., BCNU, bleomycin, busulfan, methotrexate) can cause lung toxicity directly or can enhance the damaging effects of radiation. Fractionation of radiation and lung shielding can decrease radiation toxicity. Prophylaxis strategies focus on decreasing the risks of infections post-HCT, especially among patients with chronic GVHD.

BOS occurs in 2-14\% of allogeneic HCT recipients and is almost exclusively seen among patients with chronic GVHD; some experts classify BOS as pulmonary GVHD. ${ }^{(29-31)}$ BOS may develop in patients with no other clinical manifestations of GVHD. BOS is characterized by the new onset of an obstructive lung defect and clinically manifests as dyspnea on exertion, cough or wheezing. Patients may be asymptomatic early in the disease process. BOS is clinically diagnosed when all of the following criteria are met together with active chronic GVHD in at least one organ other than the lung: (1) forced expiratory volume in one second (FEV1) / forced vital capacity ratio $<0.7$ and FEV $1<75 \%$ of predicted, (2) evidence of air trapping or small airway thickening or bronchiectasis on high resolution chest computed tomography, residual volume $>120 \%$, or pathologic confirmation of constrictive bronchiolitis, and (3) absence of infection in the respiratory tract, documented with investigations (e.g. bronchoalveolar lavage) directed by clinical symptoms. Some experts consider a decrease in the FEV1 of $10 \%$ or greater from pre-transplant baseline as a diagnostic criterion for BOS or an indication for more frequent followup pulmonary function test (PFT) assessments. The value of using spirometry to screen for BOS in the absence of symptoms is not well defined. Treatment of BOS includes immunosuppressive agents such as corticosteroids, calcineurin inhibitors, sirolimus and anti-thymocyte globulin. The prognosis of BOS is poor, and 5-year survival rates are $<20 \%$ if patients do not respond to initial treatment. ${ }^{(30,31)}$

COP, previously known as bronchiolitis obliterans organizing pneumonia, is a clinicopathologic syndrome that involves the bronchioles, alveolar ducts and the alveoli and is the result of a variety of toxic, immunological or inflammatory injuries to the lungs. COP presents typically in the first 6 to 12 months post-transplantation, although later onset may occur, especially in patients with chronic GVHD. Clinical presentation includes non-productive cough, low grade fevers and dyspnea. Radiologic imaging may reveal patchy consolidation with ground glass or nodular infiltrates. Pulmonary function tests typically show a restrictive pattern. Biopsy may be needed to confirm the diagnosis of COP. Mainstay of treatment is corticosteroids and $80 \%$ of patients can be expected to recover, but relapses are common if steroids are rapidly tapered. This complication is rare after transplantation and no specific screening tests are available for early diagnosis and prevention.

Recurrent sino-pulmonary infections can occur in patients with delayed immune reconstitution and chronic GVHD (see section on "Immunity and infections"). Appropriate vaccination is recommended, and in patients with ongoing immune deficiency and infections, monitoring of immune globulin levels should be considered with targeted replacement as recommended elsewhere in these guidelines.

Other rare late complications involving the lung include diffuse alveolar hemorrhage, pulmonary thrombo-embolism, pulmonary veno-occlusive disease and pleural effusions.

\section{Recommendations}

- Routine clinical assessment by history and physical exam for pulmonary complications is recommended for all patients at six months, one year and yearly thereafter. 
- Some experts recommend earlier and more frequent clinical assessments including PFT's in patients with chronic GVHD.

- History of smoking should be assessed and patients who smoke or are at risk for passive smoking should be counseled regarding smoking cessation.

- In patients with symptoms or signs of lung compromise, PFT's and focused radiologic assessment should be performed as clinically indicated. Followup evaluations should be guided by clinical circumstances for patients with recognized defects.

\section{Cardiac and vascular complications}

In comparison to other complications, clinically evident cardiac and cardiovascular complications after HCT are rare. Cardiac toxicity accounts for late deaths in $2 \%$ autologous and $3 \%$ of allogeneic HCT recipients. However, it is likely that cardiac and vascular complications are still underestimated. Experiences of cancer survivorship in the non-transplant setting may provide an estimate of the magnitude of risk in HCT recipients. In a cohort of 1474 long-term survivors with Hodgkin lymphoma (among whom 84\% received mediastinal radiation), the risk of cardiac and cardiovascular diseases was three to five times increased compared to a general population. ${ }^{(32)}$ Therefore, cardiac and cardiovascular complications may increase with longer follow-up after HCT.

Late cardiac events can appear years and even decades after HCT, and may manifest as subclinical abnormalities or present as overt congestive heart failure or angina. The cardiac complications include any cardiac dysfunction due to cardiomyopathy, valvular anomaly, or conduction anomaly. Many factors are involved, such as the cumulative exposure to anthracyclines and chest radiation prior to HCT, cardiac function before transplantation, intensity and type of conditioning regimen used, as well as post-transplant factors. Previous use of cardiotoxic chemotherapy and chest radiation plays a major role. For patients with non-malignant diseases such as hemoglobinopathy or aplastic anemia, transfusion history and the resultant iron overload may be important. With advancing age at time of HCT, common pre-existing cardiac diseases may be increased. Assessment prior to transplantation for all HCT recipients should include inquiry about exposure to pre-transplant chemotherapy (e.g., cumulative dose of anthracyclines) and chest and neck radiation therapy, and evaluation of pre-existing cardiac and cardiovascular disease.

Anthracycline cardiomyopathy is characterized by a dose-dependent progressive decrease in systolic left ventricular function. At total doses of less than $400 \mathrm{mg} / \mathrm{m}^{2}$ body surface area, the incidence of congestive heart failure is $0.14 \%$; this incidence increases to $7 \%$ at a dose of $550 \mathrm{mg} / \mathrm{m}^{2}$ and to $18 \%$ at a dose of $700 \mathrm{mg} / \mathrm{m}^{2}$. Mediastinal radiotherapy applied before HCT can cause a variety of cardiac complications by producing inflammation and fibrosis of all structures of the heart. Restrictive cardiomyopathy, fibrosis of the electrical conduction pathways with arrhythmias, and autonomic dysfunction, as well valvular defects, with leftsided valve regurgitation and valve thickening are the deleterious consequences.

Cardiovascular disease involves changes of the whole arterial vascular network and can include cerebrovascular disease, ischemic heart disease and peripheral arterial disease after HCT. These cardiovascular events may have diverse clinical manifestations, such as stroke, transient ischemic attack, myocardial infarction, angina pectoris, chronic coronary artery disease, ischemic leg pain or gangrene.

In a retrospective single center study, the cumulative incidence of a cardiovascular complication was $22 \%$ at 25 years after allogeneic $\mathrm{HCT}^{(33)}$ The relative risk of developing a late arterial event was significantly higher after allogeneic than after autologous HCT, supporting the hypothesis that the allo-reaction may be involved in the atherosclerotic process. The established cardiovascular risk factors (hypertension, dyslipidemia, diabetes, smoking, physical inactivity) were associated with higher risks of cardiovascular complications post-transplantation. Some conditioning regimens may have inherent cardiac toxicity with long-term cardiac consequences. ${ }^{(34)}$

A high prevalence of metabolic syndrome, elevated triglycerides, elevated blood pressure, abdominal obesity and diabetes has been reported among allogeneic HCT survivors, even when off immunosuppressive treatment. Prolonged and intensified immunosuppressive treatment, post-transplant endocrine dysfunction and insulin and/or leptin resistance could be some of the possible causes. Although studies supporting evidence based guidelines are lacking in HCT, prevention and early treatment of the cardiovascular risk factors may decrease the risk of late cardiovascular complications after HCT. ${ }^{(35)}$

\section{Recommendations}

- Routine clinical assessment and cardiovascular risk factor evaluation for all HCT recipients at 1 year and yearly thereafter. More frequent assessments and if clinically appropriate, extended cardiac evaluations (e.g., electrocardiogram, echocardiogram) may be indicated in patients at high-risk for cardiac complications (e.g., patients with Hodgkin lymphoma who have received mediastinal radiation therapy, patients with amyloidosis, and patients with preexisting cardiac and vascular abnormalities).

-Education and counseling on "heart" healthy life style (regular exercise, maintaining healthy weight, no smoking, dietary counseling) for all HCT recipients (see section on "General screening and preventive health").

- Appropriate treatment of cardiovascular risk factors such as diabetes, hypertension and dyslipidemia for all HCT recipients. Among patients started on drug therapy for dyslipidemia, followup assessments should be performed 
based on published guidelines (fasting lipid panel every 6-8 weeks till treatment goal is achieved and then every 4-6 months). ${ }^{(36)}$

- Endocarditis prophylaxis in HCT recipients according to the recommendations of the American Heart Association. ${ }^{(15)}$

\section{Liver complications}

Late liver complications are most commonly related to medications, chronic GVHD, hepatitis B or C virus (HCV), or iron overload. ${ }^{(37)}$ The etiology of liver dysfunction may be multifactorial, and a careful history, physical examination, and review of medications can often provide clues. In addition, the time course of onset and pattern of liver function test abnormalities, history of pre-transplant hepatitis, diagnosis of GVHD at other sites, and number of blood transfusions pre- and post-transplantation can be useful in determining the etiology of liver disease.

Chronic GVHD is a major cause of liver dysfunction after transplantation and can manifest with elevations of serum alanine transaminase, alkaline phosphatase, and gamma glutamyl transferase. Evaluation should exclude other causes of liver dysfunction (e.g., viral infections, drug injury). Liver biopsy should be performed to confirm the diagnosis when liver dysfunction occurs as the only manifestation of chronic GVHD and systemic immunosuppression is being considered. Immunosuppressive therapy is indicated for liver chronic GVHD; ursodeoxycholic acid may be used as an adjunct. Liver transplantation has successfully been performed in several rare cases of progressive liver failure. ${ }^{(38)}$

Long-term survivors with hepatitis B generally have mild to moderate liver disease. Chronic HCV infection is often asymptomatic with fluctuating transaminase levels as the only manifestation during the first decade following transplantation. However, the cumulative incidence of $\mathrm{HCV}$ progressing to cirrhosis is $11 \%$ at 15 years and $24 \%$ at 20 years, being more rapid in transplant than non-transplant patients (18 versus 40 years). ${ }^{(39)}$ Extrahepatic HCV disease and genotype 3 are associated with progression to cirrhosis. In patients with known HCV infection, liver biopsy can be considered at eight to ten years after transplantation to assess for the presence of cirrhosis.

HCT recipients are at risk of developing iron overload primarily from red blood cell (RBC) transfusions as part of their supportive care both pre- and post- transplantation, although increased iron absorption due to ineffective erythropoiesis and a carrier state for hereditary hemochromatosis, if present, may also contribute. ${ }^{(40)}$ Iron overload in late survivors has been associated with increased infections and may mimic hepatic chronic GVHD. Although serum ferritin is a sensitive test for iron load, as an acute phase reactant, it is not a specific test. When iron overload is suspected, the hepatic iron content should be estimated by appropriate imaging (specialized magnetic resonance imaging [MRI] protocols or superconducting quantum interference device [SQUID]) or liver biopsy. MRI and SQUID are noninvasive tests and have been shown to be sensitive and specific for quantifying liver iron content. These are the preferred methods unless a tissue sample is needed to assess for other potential etiologies of liver dysfunction. Survivors with mild iron overload may not require any therapy, as there are reports of iron load decreasing with time, but should be counseled to avoid iron supplements and alcohol ingestion. Although more data is needed to determine the incidence of end organ damage from iron overload, patients with significant iron overload (e.g., $>7 \mathrm{mg} / \mathrm{gm}$ dry weight liver iron) and liver dysfunction are candidates for phlebotomy or iron-chelation therapy. Ironchelation therapy prior to or early post-transplant is being investigated in patients with pre-transplant iron overload. Among patients who are at risk for iron overload and require vitamin supplementation, iron-free preparations should be considered.

HCT recipients who have thalassemia or have been heavily transfused pre-transplantation (e.g. other hemoglobinopathies and bone marrow failure syndromes) are particularly at risk for iron overload and acquired HBV and $\mathrm{HCV}$ infections.

\section{Recommendations}

- Liver function tests (total bilirubin, alkaline phosphatase, and transaminases) should be performed every 3-6 months for the first year and then at least yearly thereafter. More frequent assessments may be needed based on an individual patient's medical status (e.g., patients with GVHD), and particularly in allogeneic transplant survivors.

- Patients with hepatitis B and C should have viral load monitored by polymerase chain reaction (PCR) and consultation with liver and infectious disease specialists for antiviral therapy is advised. Liver specialists may recommend a liver biopsy in patients with chronic HCV infection to determine the extent of cirrhosis. This is particularly important in patients 8-10 years post transplant

- Serum ferritin should be measured at one year post transplant in patients who received $\mathrm{RBC}$ infusions pre- or post-transplant. Subsequent monitoring with serum ferritin should be considered among patients with elevated levels, especially in the presence of abnormal liver function tests, continued RBC transfusions, or $\mathrm{HCV}$ infection. Additional diagnostic testing (e.g., liver biopsy, MRI or SQUID) may be indicated if therapy is contemplated for suspected iron overload.

\section{Renal and genitourinary complications}

Renal dysfunction among HCT survivors can be caused by a number of exposures in the pre-, peri- and post-transplant period. The incidence of chronic kidney disease (CKD), defined as sustained decrease in glomerular filtration rate 
below $60 \mathrm{~mL} / \mathrm{min} / 1.73 \mathrm{~m}^{2}$, has been reported to range from $5-65 \%{ }^{(41,42)} \mathrm{CKD}$ usually becomes apparent 6 to 12 months after transplant, although it can occur earlier as well as much later post-transplantation. Renal dysfunction may present as thrombotic micro-angiopathy, glomerulonephritis or nephrotic syndrome and radiation nephritis may occur after exposure to TBI. The majority of patients have an idiopathic form of CKD, which is not associated with thrombotic microangiopathy or nephrotic syndrome and has a multifactorial etiology.

Risk factors for CKD in long-term survivors of HCT include older age at HCT, diagnosis (e.g. myeloma) and pretransplant renal function and therapy exposures (e.g. platinum compounds), acute and chronic GVHD, use of TBI in conditioning regimen, and exposure to medications to prevent or treat GVHD (e.g. calcineurin inhibitors) and certain antimicrobials (e.g. acyclovir, amphotericin B, aminoglycoside antibiotics)..$^{(42,43)}$ Antibiotics and antifungal agents cause tubular rather than glomerular damage. Calcineurin inhibitors can cause glomerular thrombosis and tubular injury. A long term syndrome of calcineurin inhibitor associated renal injury can affect both renal arterioles and tubules and can be accompanied by interstitial fibrosis. CMV infection has also been associated with glomerular injury and the use of foscarnet for CMV infection can further induce tubulointerstitial nephritis and irreversible damage due to crystallization within the renal tubules. Radiation exposure (e.g. TBI) can lead to degeneration and sclerosis of arterioles and secondary destruction of glomeruli and tubules.

Patients with substantial hemorrhagic cystitis in the early post-transplant period experience a greater risk of later bladder wall scarring and contraction. Evaluation and treatment of polyoma or adeno viruses may be warranted in some patients with hemorrhagic cystitis, especially if they have received extended duration of immunosuppressive therapy. Patients receiving immunosuppressive therapy for chronic GVHD, particularly women with GVHD of the vulva and vagina are at risk of recurrent urinary tract infections.

Recommendations regarding complications of the genital and reproductive organs are also addressed in the "Endocrine complications" and "Muco-cutaneous complications" sections.

\section{Recommendations}

- Blood pressure should be checked at every clinic visit, and hypertension should be investigated and managed appropriately in all HCT recipients (see section on "General screening and preventive health").

- Renal function should be evaluated at six months, one year and at least yearly thereafter for all HCT recipients. Screening should include assessment of BUN, creatinine and urine protein. Further workup (e.g. renal ultrasound, renal biopsy), as clinically indicated should be pursued in patients with late onset acute renal failure or CKD post-transplantation. More frequent assessments may be needed based on an individual patient's medical status (e.g., ongoing therapy with calcineurin inhibitors).

- In patients with progressive CKD, avoid nephrotoxins and consider early referral to a nephrologist for evaluation and treatment.

\section{Complications of muscle and connective tissue}

Major late complications affecting muscle and connective tissue after HCT include steroid-induced myopathy, fasciitis/scleroderma and polymyositis. One casematched control study reported that $35 \%$ of 10 -year survivors after HSCT still complain of musculoskeletal stiffness, cramps, weakness and joint swelling, and the incidence of musculoskeletal problems was significantly higher than controls. ${ }^{(44)}$ Possible causes of these problems may include sedentary lifestyle combined with muscle loss, myopathy or fibromyalgia related to steroid treatment, or scleroderma/ fasciitis related to chronic GVHD.

Myopathy after HCT is one of the most frequent complications of long-term steroid therapy for chronic GVHD. It is associated with moderate to severe functional impairment and may be associated with an increased risk of mortality. Proximal lower extremity muscles are commonly involved with the quadriceps muscle being most severely affected. The myopathy progresses insidiously in most cases. Clinical observation of a patient changing position from a supine to sitting or sitting to standing may reveal early myopathy. The use of a questionnaire such as the Human Activity Profile (HAP) may lead to its early detection. ${ }^{(45)}$ Post-transplant fatigue contributes to inactivity which exacerbates muscle atrophy. Therefore, it is also important to encourage progressively increasing physical activity to stop this vicious cycle.

Myositis or polymyositis is a distinctive feature of chronic GVHD as defined by NIH consensus criteria. ${ }^{(29)}$ Although the incidence of myositis in patients with chronic GVHD is much higher than in the general population, it is a rare complication after HCT. Chronic GVHD associated polymyositis or myopathy usually occurs $2-5$ years after HCT and the common presenting symptoms are moderate to severe proximal muscle weakness and/or myalgia. Lower extremities are more commonly involved. This syndrome may be hard to distinguish from steroid induced myopathy. The majority of patients have elevated serum creatinine kinase (CK), a myopathic pattern on electromyography (EMG), a largely peri-fascicular lymphocytic infiltration on muscle biopsy and very favorable response to immunosuppressive therapy. ${ }^{(46)}$ It is often a challenge to differentiate the muscular weakness of chronic GVHD associated myositis or myopathy from that of steroid myopathy/peripheral neuropathy as a few patients with chronic GVHD associated 
myopathy have a normal CK and lack lymphocytic infiltration in the muscle biopsy.

Sclerosis can affect the skin and subcutaneous tissues including fasciae, joints and the musculoskeletal system with varying degrees of severity and is a diagnostic feature of chronic GVHD. Early involvement of fasciae and tendons is associated with edema and an eosinophilic infiltrate, with later progression to fibrosis and joint contractures, most commonly in fingers, wrists, shoulders, elbows and ankles. Inflammation of the synovium may produce joint effusion. As sclerosis progresses insidiously, early detection is often difficult. Aggressive and prolonged immunosuppressive therapy is necessary to prevent progression of contractures, but it is usually ineffective at reversing established contractures. Early intervention and rehabilitation become essential to restore range of motion and strength. Stretching exercises and myofascial massage are important to help improve the range of motion of affected joints and to restore functions of daily living. ${ }^{(18)}$ Regular survey of range of motion at all target joints by clinicians as well as patients is also essential to detect early and potentially reversible limitation of movement.

The presence of a variety of auto-antibodies such as anti-smooth muscle, anti-nuclear and anti-mitochondrial antibodies after HCT has been observed, but in most cases they are not associated with any clinical symptoms. However, in rare cases donor-derived anti-acetylcholine receptor antibodies may be present with clinical manifestations of myasthenia gravis. ${ }^{(47)}$ Adoptive transfer of abnormal lymphocyte clones has been suggested as a possible mechanism, but immune dysregulation associated with concomitant chronic GVHD might be a contributing factor.

\section{Recommendations}

- All HCT recipients should follow general population age-specific guidelines for physical activity (See section on "General screening and preventive health").

- For patients on corticosteroids, frequent clinical evaluation is recommended for steroid-induced myopathy by manual muscle tests or by assessing patients' ability to go from a sitting to a standing position.

- Patients with muscle weakness, myalgias, or arthralgias should be evaluated for possible chronic GVHD or steroid associated myositis, and other muscular disorders (e.g. myasthenia gravis).

- Among patients with chronic GVHD, joint range of motion should be evaluated to detect sclerotic changes. Patients should also be instructed to perform self-assessment of range of motion.

- Where prolonged corticosteroid exposure is anticipated or when fasciitis or scleroderma develops, a physical therapy consultation should be considered to establish baseline function and provide range of motion and muscle strengthening exercises to minimize loss of function.

\section{Skeletal complications}

Bone density loss is a well recognized complication of HCT. There is a wide variation in the reported incidence of this complication; some studies have reported incidence rates as high as $25 \%$ for osteoporosis and $50 \%$ for osteopenia. ${ }^{(48-51)}$ Rapid loss of bone usually takes place within 6 to 12 months after transplantation. Certain patients are more susceptible to bone loss including elderly, women, patients with low body weight (body mass index $<20$ to $25 \mathrm{~kg} / \mathrm{m}^{2}$ ), patients who are physically inactive, and patients who receive extended corticosteroid therapy for their underlying disease before transplantation or for GVHD after transplantation. Some experts consider prolonged corticosteroid exposure as use of $\geq 5 \mathrm{mg}$ prednisone equivalent daily for $>3$ months. ${ }^{(52)}$ Providers should also consider corticosteroid exposure pretransplantation when determining risk for bone loss (e.g., as part of treatment regimens for lymphoma and acute lymphoblastic leukemia). The use of calcineurin inhibitors and other immunosuppressive therapy may increase the risk for this complication.

Studies suggest that both the total cumulative dose and the duration of corticosteroid therapy are important factors for the development of osteopenia. ${ }^{(48)}$ Other possible contributing factors include hypogonadism, secondary hyperparathyroidism due to the decrease in serum levels of calcium and vitamin $\mathrm{D}$, and direct toxicity from conditioning to bone cells and bone marrow stromal cells. Standard preventive measures include adequate physical activity in the post-transplant period, use of supplemental calcium and vitamin $\mathrm{D}$, and consideration of estrogen replacement therapy in deficient women.

Dual photon densitometry is currently the best tool to assess the degree of bone loss. Osteopenia and osteoporosis are differentiated by the degree of reduction in bone mass and can be quantified by $\mathrm{T}$ and $\mathrm{Z}$ scores by dual photon densitometry. Normal values of bone density have not been well established in children, although it is clear that the loss of bone density and increased risk of fracture is a significant issue in children after HCT. The femur neck and lumbar spine are the two most frequently measured sites by bone densitometry. Studies have shown differential effects in the extent and length of post-HCT bone density loss. Bone loss is more severe, persistent and resistant to therapy in cortical bones such as the femur neck than in trabecular bones such as the spine.

Treatment choices for patients with established osteopenia and osteoporosis include active exercise, calcium and vitamin D supplementation, use of estrogen replacement in women, and minimizing the total exposure and duration of steroid and other immune-suppressive therapy, if possible. ${ }^{(48)}$ Bisphosphonate therapy should be considered for treatment of patients with established osteopenia and osteoporosis, patients with evidence of progressive bone density loss, and patients at high risk for bone loss (e.g. 
patients with GVHD on extended steroid therapy). The optimal schedule and duration of bisphosphonate therapy in HCT is not well established. Bisphosphonate therapy has also been used in addition to calcium and vitamin D supplementation as a preventive measure for patients at high risk for osteopenia and osteoporosis, although the data for this intervention are less clear. Osteonecrosis of the jaw has been reported in patients receiving bisphosphonates for osteoporosis, especially among those undergoing oral procedures while on these agents. ${ }^{(53)}$ If appropriate, dental evaluation should be performed before starting bisphosphonates in order to detect and correct any dental problems. Long term use of bisphosphonates may be associated with subtrochanteric fractures of the femur; extended duration of therapy with these agents should be carefully considered until more information about this association becomes available. ${ }^{(54)}$

Avascular necrosis (AVN) has been described in 4\%$19 \%$ of HCT survivors. In addition to the risk factors for post-HCT bone loss, inflammatory microvascular changes related to GVHD or other factors may contribute to this complication. ${ }^{(55,56)}$ TBI has been associated with a higher incidence of AVN in some reports. Joint pain or discomfort is usually the first manifestation of AVN and standard radiographic evaluation may not detect abnormalities until late in the disease course. Joint symptoms in patients at risk should prompt MRI for early detection. While the hip is the most frequently affected joint (over $80 \%$ of cases; bilateral in more than $60 \%$ ), other joints can be affected including the knees, wrists and ankles. Symptomatic relief of pain and orthopedic measures to decrease pressure on the joint can be helpful. Most adult patients with advanced AVN will require surgical intervention. Orthopedic procedures including core decompression in early cases and joint replacement provide a satisfactory outcome in most patients. However, long term follow up of these procedures is needed in younger patients with a long life expectancy.

\section{Recommendations}

- A screening dual photon densitometry should be performed at 1 year after transplantation in adult women, all allogeneic HCT recipients and patients who are at high risk for bone loss after transplantation (e.g., prolonged treatment with corticosteroids or calcineurin inhibitors). Repeat densitometry should be performed in those with recognized defects, ongoing risk factors or to follow up response to therapy. Physicians should evaluate gonadal and other related endocrine abnormalities in patients with decline in bone density.

- Patients should be counseled about preventive measures for bone loss and fractures such as physical exercise, fall prevention, and vitamin $\mathrm{D}$ and calcium supplementation. Hormone replacement therapy should be discussed with women who have estrogen deficiency. Some experts recommend the use of bisphosphonates for patients at high risk for bone loss.

- Screening for AVN is not recommended; however, clinicians should maintain a high level of suspicion for patients with exposure to irradiation or prolonged corticosteroids and evaluate patients with joint symptoms promptly.

\section{Central and peripheral nervous system complications}

Neurological complications after HCT may affect the central and peripheral nervous system and are mostly secondary to infections, drug related toxicity and metabolic encephalopathy. The effect on cognitive function and level of alertness can be subclinical with white matter changes detected up to a year later. The reported complication rate is higher in allogeneic, especially alternative donor HCT, as compared to autologous HCT recipients. ${ }^{(57,58)}$

Complications include central nervous system infections in immunocompromised recipients and vascular complications such as stroke and calcineurin inhibitor induced neurotoxicity. Leukoencephalopathy may occur as sequela of intrathecal chemotherapy and cranial irradiation. Patients who have received TBI or cranial irradiation are at increased risk of secondary solid tumors of the brain on long term follow up. Children exposed to TBI are also at risk for developmental delays. There is growing evidence of a GVHD effect on the central nervous system. A cerebral angiitis like syndrome has been described with cerebral ischemic lesions and leukoencephalopathy secondary to GVHD. Guillain-Barre like syndrome with peripheral neuropathy and chronic demyelinating polyneuropathy related to GVHD has been reported. ${ }^{(47,59,60)}$ Peripheral neuropathy after HCT may be related to chemotherapy exposure.

Neuropsychological deficits have been described in nearly $20 \%$ of recipients and cognitive deficits in approximately $10 \%$ of HCT recipients. Patients with a history of central nervous system disease (e.g., adenosine deaminase deficiency associated severe combined immunodeficiency) and children treated with cranial radiation alone or in combination with chemotherapy are at higher risk. Cognitive changes may be subtle and difficult to detect making it imperative for the clinician to be vigilant even in patients who do not have any specific complaints. ${ }^{(59,61)}$ Neurocognitive function generally improves over time, but long-term deficits can remain in more than $40 \%$ of survivors. ${ }^{(62)}$

\section{Recommendations}

- All HCT recipients should undergo clinical assessment for symptoms or signs of neurologic dysfunction at 1 year after HCT and at least yearly thereafter. Earlier and more frequent evaluations may be considered in high-risk patients (e.g., allogeneic HCT recipients, patients receiving prolonged immune suppression with calcineurin inhibitors, 
patients receiving TBI, cranial radiation or intrathecal chemotherapy and patients with chronic GVHD).

- Evaluation for cognitive developmental milestones should be performed at least annually in pediatric patients. Adult patients should be queried annually for changes in cognitive function, which may be subtle.

- Further evaluation (e.g., MRI, nerve conduction studies, electromyography, neuropsychiatry testing) may be warranted in recipients with symptoms or signs of neurologic or cognitive dysfunction.

\section{Endocrine complications}

Chemotherapy, radiation therapy and HCT can all result in impairment of endocrine function. The most significant endocrine complications are associated with exposure to radiation and chemotherapeutic agents (e.g., busulfan), chronic GVHD, and prolonged corticosteroid exposure. ${ }^{(63)}$

Subclinical, compensated hypothyroidism, with elevated TSH and normal serum free T4 levels, occurs in $7-15 \%$ of patients in the first year after transplantation. The reported incidence of frank hypothyroidism is variable depending upon risk factors in the population studied. Single-dose ablative TBI is associated with a $50 \%$ incidence of overt hypothyroidism, whereas fractionated TBI is associated with an incidence of about $15 \%$. The incidence reported after busulfan and cyclophosphamide conditioning is $11 \%$. Treatments given before transplantation likely also contribute to the risk of thyroid abnormalities. The median time to diagnosis of hypothyroidism is nearly 4 years after HCT or TBI exposure. When TSH is elevated with normal T4 levels, assessment should be repeated in two months, or therapy should be initiated at the discretion of the treating physician. Patients who start thyroid hormone replacement should be reassessed at about six weeks after initiation of therapy. Further individual dose adjustment should be based on periodic thyroid assessment, most often recommended at 6-month intervals. Autoimmune thyroiditis may also occur following radiation. Radiation to the neck and total body irradiation has been associated with dose-related increases in risk of thyroid malignancy, often with long latent periods. ${ }^{(64)}$

Gonadal dysfunction is highly prevalent in HCT recipients, with rates as high as $92 \%$ for males and $99 \%$ for females. The degree of dysfunction is dependent on age, gender, pre-transplant therapy, and conditioning regimen. ${ }^{(65)}$ Although the risk of gonadal failure is high in all individuals, women generally experience higher rates of failure than do men.

Women are at high risk of hypergonadotropic hypogonadism after HCT. ${ }^{(66)}$ Hypogonadism is nearly universal after high dose irradiation or busulfan. Risk is lower with cyclophosphamide alone. In general, ovarian endocrine failure is irreversible in adult women, but younger women, particularly prepubescent girls, have a better opportunity for recovery of gonadal function.
Fractionation of radiation reduces the risk compared with unfractionated radiation. Prepubertal girls should be monitored closely for onset of puberty and, if puberty is not experienced by age 12 to 13 , be referred for full endocrinology evaluation and consideration of hormone supplementation. Adult women should be evaluated by a gynecologist and may require hormone replacement therapy to maintain libido, sexual function, and bone density. Libido is often decreased and only partially corrected by hormone replacement therapy in women. Vaginal GVHD may result in strictures and synechiae. Supplemental vaginal lubrication is available and should be discussed by the treating physician.

Most men have normal testosterone levels after transplantation, although germ cell damage (infertility) is a near-universal finding in men exposed to high doses of radiation or chemotherapy. Most reports suggest that prepubertal boys experience normal puberty and demonstrate normal testosterone levels following HCT. ${ }^{(6)}$ Testing and consideration of hormone replacement therapy for men is recommended based on symptoms. Failure to progress through puberty in a timely fashion should prompt referral for a full endocrinology evaluation.

Transplant recipients have a low incidence of primary adrenal failure after HCT. Chronic therapy with corticosteroids for GVHD will suppress the pituitary-adrenal axis, but function usually recovers gradually once exogenous corticosteroid exposure ends. Greater length and intensity of exposure is generally associated with longer persistence of adrenal suppression. Patients with prolonged exposure to corticosteroids after HCT should have adrenal axis testing when withdrawing corticosteroids, particularly if symptoms of adrenal insufficiency develop. Clinicians should maintain awareness of possible hypoadrenalism in patients receiving long term corticosteroids who develop acute illness and consider 'stress dose' corticosteroids.

Growth in children may be adversely affected by HCT, depending upon their pre-transplant therapy and conditioning regimen. ${ }^{(65,66)} \mathrm{A}$ large body of data suggests that radiation is associated with growth defects in children who receive HCT. Cranial radiation, in particular, increases the risk of diminished growth in children. Some reports suggest that chemotherapy alone may cause growth deficiencies. Growth is a complicated process and may be adversely impacted by many additional factors, including general illness, nutritional deficits, hormonal deficiencies, long-term corticosteroids, and GVHD. The risk of impaired growth is greatest in the youngest children. Children should be closely monitored for appropriate growth velocity after HCT. A pediatric endocrinologist should evaluate children who do not achieve adequate growth, and assessment of growth hormone levels should be considered. Growth hormone deficiency following TBI has been demonstrated in some studies, but not in others. Since growth failure is likely to be multifactorial, consideration must be given to causes other than inadequate growth hormone. The benefits 
of growth hormone supplementation are unclear. However, in children with demonstrated deficiency, supplementation is commonly prescribed.

\section{Recommendations}

- Thyroid function tests (TSH, T3, and free T4) should be performed at one year and yearly thereafter in all transplant recipients and additionally if relevant symptoms develop.

- Clinical and endocrinologic gonadal assessment at one year after HCT is recommended for all women who were post-pubertal at the time of transplantation. Frequency of subsequent assessments should be guided by clinical need (e.g., menopausal status). Women should have annual gynecologic evaluation as part of general health screening, at which time, hormone replacement therapy should be addressed for those who are post-menopausal.

- Gonadal function in men, particularly FSH, LH, and testosterone, should be assessed if symptoms warrant (lack of libido or erectile dysfunction). Consider referral to an endocrinologist for men who may need testosterone replacement therapy.

- Clinical and endocrinologic gonadal assessment of pre-pubertal boys and girls should be initiated 6-12 months after transplantation, with further follow-up schedule determined in consultation with an endocrinologist.

- Patients withdrawing from prolonged corticosteroid usage should have slow terminal tapering of corticosteroids; stress doses of corticosteroids may be warranted during acute illness in patients who have been on chronic corticosteroids in the past.

- Growth velocity should be monitored every year in all children, with assessment of thyroid function and growth hormone if growth velocity is abnormal.

\section{Muco-cutaneous complications}

Late complications involving skin and appendages are frequent after $\mathrm{HCT}{ }^{(67)}$ Nearly $70 \%$ of patients with chronic GVHD experience skin involvement. Early changes of lichenplanus like or papulosquamous lesions may progress to sclerosis or poikiloderma and can be associated with skin ulcers and subsequent infections. Alopecia, thinning of scalp hair, nail dystrophy, sweat impairment and skin dyspigmentation are common complications after chronic GVHD.

HCT survivors, especially recipients of allogeneic HCT, are at risk for developing secondary cancers of the skin. ${ }^{(24)}$ Patients should be counseled about early detection and prevention of skin cancers including avoiding excessive sun exposure, using adequate skin protection and periodic self examination of the skin with prompt referral to a dermatologist for further evaluation and treatment of suspicious skin lesions.

Severe genital GVHD may develop in approximately $12 \%$ of women with or without associated systemic
GVHD ${ }^{(68,69)}$ Patients may present with excoriated or ulcerated mucosa, fissures, narrowing of introitus, or vaginal scarring and obliteration that may lead to hematocolpos. Initial symptoms may be mild and nonspecific such as dryness, dyspareunia or post coital bleeding and if not recognized they may lead to important sexual dysfunction. Careful questioning and examination should be performed as patients without sexual activity may not detect these abnormalities and sexually active patients may not disclose relevant symptoms. Biopsy may be needed to establish the diagnosis. Care should be taken when reducing systemic immunosuppression as reactivation of genital GVHD may occur. Vaginal strictures may limit the performance of routine Papanicolaou smears as well as sexual intercourse. Treatment of vaginal GVHD includes topical steroids, topical cyclosporine and vaginal dilators. Surgical intervention can be used to treat severe cases. In contrast to chronic GVHD, patients with hypo-estrogenism due to premature menopause may present with thin and pale vulvar mucosa that responds well to lubricants and topical estrogens. However, patients may have changes due to GVHD and hypo-estrogenism concurrently. Genital involvement with GVHD is less common in men and may result in phimosis.

\section{Recommendations}

- Patients should perform routine self examination of the skin and avoid excessive exposure of sunlight without adequate protection.

- All women recipients of allogeneic HCT should have clinical screening for symptoms of genital GVHD. Women who have established chronic GVHD should have gynecological exam to screen for genital involvement.

- Patients should be counseled about self examination of the vaginal area, general hygiene measures, and early recognition of local symptoms. Application of topical vaginal immunosuppressive agents, such as ultrahigh potency corticosteroids or calcineurin inhibitors, prescription of systemic hormonal replacement therapy if indicated, and the use of vaginal dilatators should be initiated early in the course of the disease.

\section{Secondary cancers}

Second malignancies after HCT are a devastating late complication. Patients receiving allogeneic HCT have a two to three fold increased risk of developing solid tumors, compared to an age-, gender-, and region-adjusted population. ${ }^{(59)}$ Nearly all cancer types are described after allogeneic and autologous transplant, including oral cancers, as mentioned above. Risk factors include radiation therapy, length, and intensity of immunosuppression and chronic GVHD. ${ }^{(26)}$ However, a recent long-term follow-up analysis of patients transplanted after myeloablative doses of busulfan and cyclophosphamide found similar increased risk. ${ }^{(25)}$ Risk 
increases with time after transplantation, particularly for radiation-related malignancies. Recent analyses suggest that risk of radiation-related (sarcoma, breast and thyroid cancers) and non-radiation related (squamous cell carcinoma linked to chronic GVHD) solid tumors continues to increase beyond 10 -years post transplantation. ${ }^{(24,26)}$ Children who have received cranial irradiation are at risk for developing brain tumors. HCT recipients with Fanconi's anemia are also at risk for developing oro-pharyngeal cancers. Providers can consider vaccination against human papilloma virus according to country-specific general population recommendations. ${ }^{(10)}$ All patients should at least receive country-specific general population recommendations for screening for cancers. Screening for breast cancer is recommended at an earlier age ( 25 years or eight years after radiation, whichever occurs later) but no later than age 40 among recipients of TBI or chest irradiation. Early referral to a dermatologist should be considered in patients with skin lesions suspicious for cancer.

Risk of secondary leukemia or myelodysplasia after autologous HCT is also higher than anticipated, with an overall incidence of about $4 \%$ at seven years after transplantation; with a median onset of 2.5 years (range, three months to seven years) post-transplantation. Risk appears to be increased for patients receiving prior alkylator therapy, prolonged administration of conventional chemotherapy, and higher doses of pre-transplant irradiation. ${ }^{(70)}$

Post transplant lymphoproliferative disorders (PTLD) are a rare complication of allogeneic HCT associated with greater donor-recipient HLA disparity, T cell depletion and GVHD. ${ }^{(71)}$ Overall incidence is $1 \%$ at ten years after HCT. Although these usually occur early (within six months of transplantation), PTLD is reported as late as eight years after HCT. The majority of PTLD are associated with EpsteinBarr Virus (EBV) infection. Quantitative PCR detection of EBV reactivation allows prompt initiation of anti-CD20 monoclonal antibody therapy before development of frank PTLD. ${ }^{(59)}$

\section{Recommendations}

- Exposure to radiation, and photosensitizing effects of many commonly used transplantation-related medications increases the risk of skin cancers among $\mathrm{HCT}$ recipients. All HCT recipients should be encouraged to reduce UV skin exposure through use of high SPF sunscreens or skin coverage.

- All patients should be advised of the risks of secondary malignancies annually and encouraged to routinely perform recommended screening self-examination such as genital/testicular and skin examination. Women should discuss breast self-examination with their physicians. All patients should be encouraged to avoid highrisk behaviors as recommended under General health and Preventive screening section, including avoidance of tobacco, passive tobacco exposure or excessive unprotected skin UV exposure.

- Screening clinical assessment should be performed yearly, and should include symptom review for secondary malignancies. Clinical examination and screening for secondary malignancies should follow the recommendations outlined under the General health and Preventive screening section. In women with radiation exposure (e.g. TBI or radiation to the chest region), initiation of screening mammography should occur at age 25 or eight years after radiation, whichever occurs later, but no later than age 40 years. Particular attention to oral malignancies should be paid to patients with previous severe chronic GVHD of the oral and pharyngeal mucosa.

\section{Psychosocial adjustment and sexual complications}

Depressive symptoms and psychological distress are frequently observed in HCT survivors. Fatigue, anger, insomnia, and problems with marital relationships may also be seen. Pediatric patients may experience altered behavior patterns, changes in social habits, and changes in academic/ school behavior. At the transition from acute convalescence to long-term follow-up, psychological distress may increase rather than abate as the patient and his/her family must cope with changes in roles, employment situations, and financial difficulties. Spouses and other caregivers may also exhibit high levels of depression and psychological distress. They often report loneliness and low levels of perceived social support. Children may suffer from separation from one or both parents and the consequences of stress and upheaval in the family. At a minimum, screening for depression is recommended every 6-12 months after transplantation as per the general health maintenance section below. Specific tools for screening for psychosocial difficulties after HCT are also available and could be used with a similar frequency to depression screening. Sexual dysfunction occurs in a significant number of survivors and may be multifactorial in origin, from depression to gonadal hormonal deficiency.

\section{Recommendations}

-A high level of vigilance for psychological symptoms should be maintained. Clinical assessment is recommended throughout the recovery period, at six months, at one year, and at least yearly thereafter, with mental health professional assessment recommended for those with recognized deficits.

- Inquiry as to the level of spousal/caregiver psychological adjustment and family functioning should be performed at regular intervals.

- In adults, sexual function should be queried at six months, at one year and yearly thereafter (also see section on "Muco-cutaneous complications"). 


\section{Fertility}

Male and female HCT survivors are at risk for infertility secondary to pre-transplant and transplant related treatment exposures. ${ }^{(72,73)}$ Among transplant survivors of the child bearing age group, loss of fertility can be associated with psychological consequences that can affect quality of life. Conditioning regimens with TBI or busulfan plus cyclophosphamide can cause gonadal failure, although risk may be lower with regimens that include cyclophosphamide only. Older age at transplant and chronic GVHD are associated with low likelihood of gonadal recovery. Nonassisted natural pregnancies following gonadal recovery in women or in partners of male transplant recipients have been reported, but the estimated incidence is less than $15 \%$.

The outcome of pregnancy after transplantation is generally good, although women are at increased risk of fetal and maternal complications and post-transplant pregnancy should be considered a high-risk pregnancy. ${ }^{(73)}$ The incidence of congenital anomalies is not higher than in the normal population and the rate of miscarriage is not increased. Women exposed to TBI have a higher than normal incidence of preterm deliveries and low or very low birth weight infants. Irradiation may result in uterine vessel damage and reduce uterine volume.

A general recommendation is to delay spontaneous or assisted pregnancies for at least two years after HCT since this is the period of highest risk of relapse after transplantation. Contraception counseling in survivors after HCT with gonadal recovery is recommended and contraception is advisable if fertile or if fertility status is not known and pregnancy is not desired. Even if infertile, barrier contraception is recommended with new partners to prevent sexually transmitted diseases.

Women with gonadal recovery should also be advised about the risks of premature menopause.

\section{Recommendations}

- Consider referral to appropriate specialists for patients who are contemplating a pregnancy or are having difficulty conceiving.

- Although infertility is common, patients should be counselled regarding birth control post-transplantation.

\section{General screening and preventive health}

In addition to transplant-specific risk factors mentioned above, HCT survivors face general risks found in the nontransplanted population. In general, transplant survivors should be under the care of physicians comfortable with providing care for general health and hematology-oncology specific issues. Summarized below are screening and lifestyle recommendations for the general adult population that are also relevant for HCT survivors. Further details about screening recommendations for adults and children can be found at: http://www.uspreventiveservicestaskforce. org. ${ }^{(74,75)}$

\section{Recommended screening for all patients}

- Hypertension: Blood pressure should be checked at least every two years. In children, hypertension is defined as readings greater than the $95^{\text {th }}$ percentile for age, sex and height. Treatment is indicated for readings of greater than $140 / 90$ in adults on two separate visits at least one week apart, unless hypertension is mild or can be attributed to a temporary condition or medication (e.g., cyclosporine). Nonpharmacologic treatments may also be tried for mild hypertension and include moderate dietary sodium restriction, weight reduction in the obese, avoidance of excess alcohol intake, and regular aerobic exercise.

- Hypercholesterolemia: Cholesterol and HDL levels should be checked every five years starting at age 35 for men and 45 for women. Screening should start at age 20 for anyone who smokes, has diabetes, hypertension, obesity (body mass index $\geq 30 \mathrm{~kg} / \mathrm{m}^{2}$ ), or a family history of heart disease before age 50 for male relatives or before age 60 for female relatives. Fasting is not required for accurate measurement of cholesterol and HDL, but is required for LDL and triglycerides. As a rough guideline, total cholesterol levels $>200 \mathrm{mg} / \mathrm{dL}$ $(>5.0 \mathrm{mmol} / \mathrm{L})$ or HDL levels $<40 \mathrm{mg} / \mathrm{dL}(<1 \mathrm{mmol} / \mathrm{L})$ should be followed up by a full fasting lipid panel. Treatment goals are based on overall risk of heart disease (e.g., greater than a $10 \%$ chance of coronary heart disease in ten years). Overall risk assessment will include the following risk factors: age, sex, diabetes, clinical atherosclerotic disease, hypertension, family history, low HDL $(<40 \mathrm{mg} / \mathrm{dL}$ or $1.0 \mathrm{mmol} / \mathrm{L})$, and smoking. An online calculator is available at http:// www.nhlbi.nih.gov/guidelines/cholesterol/index.htm.

- Colorectal cancer: Screening should start at age 50 in the absence of a family history (first degree relative diagnosed with colorectal cancer before age 60). The interval of testing depends on the type of testing procedure and the prior screening results. There are several screening approaches including annual fecal occult blood testing (three cards at home), sigmoidoscopy every five years with fecal occult testing every three years, or colonoscopy every ten years. Virtual computerized tomography is a new method, currently under investigation. No one approach alone or in combination has proven superior, however a single digital rectal exam with occult blood testing is not recommended.

- Diabetes: Screening for type 2 diabetes is indicated for people every three years after age 45 or in those with sustained higher blood pressure $(>135 / 80)$ because blood pressure targets are lower for diabetics. A fasting plasma glucose $>126 \mathrm{mg} / \mathrm{dL}(>7 \mathrm{mmol} / \mathrm{L})$, confirmed by testing on another day, is diagnostic for diabetes.

- Depression: Asking two simple questions about mood and anhedonia ("Over the past two weeks, have you felt down, depressed, or hopeless?" and "Over the past 
two weeks, have you felt little interest or pleasure in doing things?") is probably as effective as longer screening tools. Frequency of screening is not stated, but it is reasonable to screen every 6-12 month post-transplantation or as clinically indicated. Affirmative answers to the questions above should trigger in depth evaluation for depression to determine the need for pharmacological or psychotherapeutic treatments.

- Sexually transmitted diseases: Chlamydia screening is recommended for women under the age of 25 who are sexually active. Screening and appropriate treatment decrease the incidence of pelvic inflammatory disease and pregnancyrelated complications, although most women will be infertile after myeloablative transplantation. Male and female survivors should be reminded that protection against sexually transmitted disease is important even when pregnancy is unlikely or impossible.

\section{Sex-specific recommendations}

Recommended screening for men:

- Prostate cancer: There is no consensus about the use of prostate-specific antigen or digital rectal examination for prostate cancer screening.

Recommended screening for women:

- Breast cancer: Screening with mammograms should start at age 40 and occur every 1-2 years. Breast self-exam is not recommended. In women exposed to $>800 \mathrm{cGy}$ radiation, screening should start at age 25 or eight years after radiation exposure, whichever is later but no later than age 40 , based on the data from Hodgkin lymphoma survivors.

- Cervical cancer: Screening with pap smears should be performed every 1-3 years in women older than 21 or within three years of initial sexual activity, whichever occurs earlier.

- Osteoporosis: Screening with a bone density test should start at age 65 for women in the general population, or if the individual's fracture risk is equivalent to a 65 year old woman (9.3\% risk at 10 years). ${ }^{(76)} \mathrm{An}$ online calculator is available to determine the 10 year risk of fracture (www.shef.ac.uk/FRAX/). Also see section on Skeletal Complications for additional recommendations for HCT recipients.

\section{Healthy lifestyle recommendations for all patients}

- Eat a healthy diet with a wide variety of foods.

- Don't smoke (passive or active exposure), chew tobacco or use illegal drugs.

- Use alcohol in moderation, generally less than two drinks per day.

- Maintain a healthy weight.

- Avoid excessive sun exposure and wear sunscreen protection for anticipated periods of long exposure.
-Follow general population age specific guidelines for physical activity (www.health.gov/paguidelines). ${ }^{(77)}$ Adults (aged 18-64) should do two hours and thirty minutes a week of moderate-intensity, or one hour and fifty minutes a week of vigorous-intensity aerobic physical activity or an equivalent combination of moderate - and vigorous-intensity aerobic physical activity. Aerobic activity should be performed in episodes of at least ten minutes. Adults should also do muscle strengthening activities that involve all major muscle groups performed on two or more days per week.

\section{Implementation of guidelines in resource limited countries}

Although the Working Group has provided recommendations that should be applicable to all HCT recipients, they recognized that resource constraints may limit their implementation, especially in certain geographic regions and developing countries. Some examples of such challenges include availability of specialists with expertise and experience in managing post-transplant complications and availability of tests and procedures. Furthermore, issues related to healthcare access (e.g., distance to transplant center or health care facility with adequate expertise and resources) may restrict the ability of some patients to obtain screening and preventive care. In circumstances where resource limitations do not allow for comprehensive evaluation and followup, health care providers should use their best clinical judgment in determining appropriate preventive care for HCT survivors based on their individual exposures and risk-factors for long-term complications.

\section{Long term followup of HCT recipients}

To facilitate transition of HCT recipients from one phase of post-transplant care to another, transplant providers should provide HCT recipients with a survivorship care plan that includes a treatment summary and a followup care plan. This document can serve as an instrument for reminding providers about appropriate surveillance for late complications based on an individual patient's risk-factors and exposures. Since survivors can be at risk for late relapse, the care plan should also include appropriate followup for the disease for which HCT was performed. Survivorship care plan instruments that are specific to HCT recipients are lacking. Until they are routinely available, providers can consider instruments that have been developed for cancer survivors in general (e.g., Livestrong Care Plan [www. livestrongcareplan.org], Passport for Care ${ }^{\circledR}$ [www.txch.org/ passportforcare]). In addition, providers can consider incorporating the patient version of these guidelines (available at www.BeTheMatch.org/Patient) into a survivorship care plan document for HCT recipients.

Long-term survivors of HCT may not receive care at their transplant center. Because of patient or center 
preference, absence of immediate transplant related complications, or distance from the transplant center, transplant recipients may transition their care back to their hematologist-oncologists, primary care physicians or other health care providers. With an increasing number of transplant survivors, it is likely that non-transplant health care providers will play a greater role in survivorship care and may need to be aware of the unique exposures, risk factors and medical issues these patients face. The working group recognized that the models and primary site for long-term followup will vary by country and available resources. On occasion, adherence to particular recommendations may be inconsistent with national or regional guidelines, the availability of specific procedures or medications, or local epidemiological conditions. Individual clinicians should practice best clinical judgment in implementing these guidelines and when caring for an individual patient, should consider age, gender, coexisting comorbidities, cancer and transplant related exposures and immediate side effects in determining patient risks for specific long-term complications. Prevention, screening and management of late complications of transplantation may require a multidisciplinary approach, with involvement of the transplant center, oncologists, subspecialists, primary care physicians, and other health care providers, as necessary.

\section{Acknowledgements}

We would like to acknowledge the following members of the Late Effects Working Group of the Asia-Pacific Blood and Marrow Transplantation Group for their review of this manuscript: Mickey Koh (Singapore), Jong Wook Lee (Korea), David Ma (Australia) and Tahir Shamsi (Pakistan).

\section{References}

1. Wingard JR, Majhail NS, Brazauskas R, Wang Z, Sobocinski KA, Jacobsohn $D$, et al. Long-term survival and late deaths after allogeneic hematopoietic cell transplantation. J Clin Oncol. 2011; 29(16):2230-9.

2. Bhatia S, Francisco L, Carter A, Sun CL, Baker KS, Gurney JG, et al. Late mortality after allogeneic hematopoietic cell transplantation and functional status of long-term survivors: report from the Bone Marrow Transplant Survivor Study. Blood. 2007;110(10): 378492.Comment in: Blood. 2008;111(3):1740-1.

3. Bhatia S, Robison LL, Francisco L, Carter A, Liu Y, Grant M, et al. Late mortality in survivors of autologous hematopoietic-cell transplantation: report from the Bone Marrow Transplant Survivor Study. Blood. 2005;105(11):4215-22.

4. Goldman JM, Majhail NS, Klein JP, Wang Z, Sobocinski KA, Arora M, et al. Relapse and late mortality in 5-year survivors of myeloablative allogeneic hematopoietic cell transplantation for chronic myeloid leukemia in first chronic phase. J Clin Oncol. 2010;28(11):1888-95.

5. Martin PJ, Counts GW Jr, Appelbaum FR, Lee SJ, Sanders JE, Deeg $\mathrm{HJ}$, et al. Life expectancy in patients surviving more than 5 years after hematopoietic cell transplantation. J Clin Oncol. 2010;28(6): 1011-6.

6. Majhail NS, Bajorunaite R, Lazarus HM, Wang Z, Klein JP, Zhang $\mathrm{MJ}$, et al. Long-term survival and late relapse in 2-year survivors of autologous haematopoietic cell transplantation for Hodgkin and non-Hodgkin lymphoma. Br J Haematol. 2009;147(1):129-39.

7. Rizzo JD, Wingard JR, Tichelli A, Lee SJ, Van Lint MT, Burns LJ, et al. Recommended screening and preventive practices for longterm survivors after hematopoietic cell transplantation: joint recommendations of the European Group for Blood and Marrow Transplantation, the Center for International Blood and Marrow Transplant Research, and the American Society of Blood and Marrow Transplantation. Biol Blood Marrow Transplant. 2006; 12(2):138-51.

8. Rizzo JD, Wingard JR, Tichelli A, Lee SJ, Van Lint MT, Burns LJ, et al. Recommended screening and preventive practices for longterm survivors after hematopoietic cell transplantation: joint recommendations of the European Group for Blood and Marrow Transplantation, Center for International Blood and Marrow Transplant Research, and the American Society for Blood and Marrow Transplantation (EBMT/CIBMTR/ASBMT). Bone Marrow Transplant. 2006;37(3):249-61.

9. Center for International Blood and Marrow Transplant Research (CIBMTR); National Marrow Donor Program (NMDP); European Blood and Marrow Transplant Group (EBMT); American Society of Blood and Marrow Transplantation (ASBMT); Canadian Blood and Marrow Transplant Group (CBMTG); Infectious Disease Society of America (IDSA); Society for Healthcare Epidemiology of America (SHEA); Association of Medical Microbiology and Infectious Diseases Canada (AMMI); Centers for Disease Control and Prevention (CDC). Guidelines for preventing infectious complications among hematopoietic cell transplant recipients: a global perspective. Bone Marrow Transplant. 2009;44(8):453-558.

10. Tomblyn M, Chiller T, Einsele H, Gress R, Sepkowitz K, Storek J, Wingard JR, Young JA, Boeckh MJ; Center for International Blood and Marrow Research; National Marrow Donor program; European Blood and MarrowTransplant Group; American Society of Blood and Marrow Transplantation; Canadian Blood and Marrow Transplant Group; Infectious Diseases Society of America; Society for Healthcare Epidemiology of America; Association of Medical Microbiology and Infectious Disease Canada; Centers for Disease Control and Prevention. Guidelines for preventing infectious complications among hematopoietic cell transplantation recipients: a global perspective. Biol Blood Marrow Transplant. 2009;15(10):1143-238. Erratun: Biol Blood Marrow Transplant. 2010 Feb;16(2):294. Boeckh, Michael A [corrected to Boeckh, Michael J].

11. Ljungman P, Cordonnier C, Einsele H, Englund J, Machado CM, Storek J, Small T; Center for International Blood and Marrow Transplant Research; National Marrow Donor Program; European Blood and Marrow Transplant Group; American Society of Blood and Marrow Transplantation; Canadian Blood and Marrow Transplant Group; Infectious Disease Society of America; Society for Healthcare Epidemiology of America; Association of Medical Microbiology and Infectious Diseases Canada; Centers for Disease Control and Prevention. Vaccination of hematopoietic cell transplant recipients. Bone Marrow Transplant. 2009;44(8):521-6.

12. Welniak LA, Blazar BR, Murphy WJ. Immunobiology of allogeneic hematopoietic stem cell transplantation. Annu Rev Immunol. 2007;25:139-70.

13. Machado CM, Martins TC, Colturato I, Leite MS, Simione AJ, Souza MP, et al. Epidemiology of neglected tropical diseases in transplant recipients. Review of the literature and experience of a Brazilian HSCT center. Rev Inst Med Trop Sao Paulo. 2009;51 (6):309-24.

14. Gea-Banacloche J, Masur H, Arns da Cunha C, Chiller T, Kirchhoff LV, Shaw P, Tomblyn M, Cordonnier C; Center for International Blood and Marrow Transplant Research; National Marrow Donor Program; European Blood and Marrow Transplant Group; American Society of Blood and Marrow Transplantation; Canadian 
Blood and Marrow Transplant Group; Infectious Disease Society of America; Society for Healthcare Epidemiology of America; Association of Medical Microbiology and Infectious Diseases Canada; Centers for Disease Control and Prevention. Regionally limited or rare infections: prevention after hematopoietic cell transplantation. Bone Marrow Transplant. 2009;44(8):489-94. Erratum in: Bone Marrow Transplant. 2010;45(4):806. Kirchoff, L [corrected to Kirchhoff, LV]; Arns da Cuhna, C [corrected to Arns da Cunha, C].

15. Wilson W, Taubert KA, Gewitz M, Lockhart PB, Baddour LM, Levison M, Bolger A, Cabell CH, Takahashi M, Baltimore RS, Newburger JW, Strom BL, Tani LY, Gerber M, Bonow RO, Pallasch T, Shulman ST, Rowley AH, Burns JC, Ferrieri P, Gardner T, Goff D, Durack DT; American Heart Association Rheumatic Fever, Endocarditis, and Kawasaki Disease Committee; American Heart Association Council on Cardiovascular Disease in the Young; American Heart Association Council on Clinical Cardiology; American Heart Association Council on Cardiovascular Surgery and Anesthesia; Quality of Care and Outcomes Research Interdisciplinary Working Group.Prevention of infective endocarditis: guidelines from the American Heart Association: a guideline from the American Heart Association Rheumatic Fever, Endocarditis, and Kawasaki Disease Committee, Council on Cardiovascular Disease in the Young, and the Council on Clinical Cardiology, Council on Cardiovascular Surgery and Anesthesia, and the Quality of Care and Outcomes Research Interdisciplinary Working Group. Circulation. 2007;116 (15):1736-54. Comment in: Rev Gastroenterol Disord. 2008 Winter;8(1):73-4; Z Gastroenterol. 2008;46(4):376-7.

16. Kim SK. Update on ocular graft versus host disease. Curr Opin Ophthalmol. 2006;17(4):344-8.

17. Flowers ME, Parker PM, Johnston LJ, Matos AV, Storer B, Bensinger WI, et al. Comparison of chronic graft-versus-host disease after transplantation of peripheral blood stem cells versus bone marrow in allogeneic recipients: long-term follow-up of a randomized trial. Blood. 2002;100(2):415-9.

18. Couriel D, Carpenter PA, Cutler C, Bolaños-Meade J, Treister NS, Gea-Banacloche J, Shaughnessy P, Hymes S, Kim S, Wayne AS, Chien JW, Neumann J, Mitchell S, Syrjala K, Moravec CK, Abramovitz L, Liebermann J, Berger A, Gerber L, Schubert M, Filipovich AH, Weisdorf D, Schubert MM, Shulman H, Schultz K, Mittelman B, Pavletic S, Vogelsang GB, Martin PJ, Lee SJ, Flowers ME. Ancillary therapy and supportive care of chronic graft-versushost disease: national institutes of health consensus development project on criteria for clinical trials in chronic Graft-versus-host disease: V. Ancillary Therapy and Ancillary therapy and supportive care of chronic graft-versus-host disease: national institutes of health consensus development project on criteria for clinical trials in chronic Graft-versus-host disease: V. Ancillary Therapy and Supportive Care Working Group Report. Biol Blood Marrow Transplant. 2006;12(4):375-96.

19. Baker KS, Gurney JG, Ness KK, Bhatia R, Forman SJ, Francisco $\mathrm{L}$, et al. Late effects in survivors of chronic myeloid leukemia treated with hematopoietic cell transplantation: results from the Bone Marrow Transplant Survivor Study. Blood. 2004;104: 1898-906.

20. Benyunes MC, Sullivan KM, Deeg HJ, Mori M, Meyer W, Fisher L, et al. Cataracts after bone marrow transplantation: long-term follow-up of adults treated with fractionated total body irradiation. Int J Radiat Oncol Biol Phys. 1995;32:661-70.

21. Tichelli A, Gratwohl A, Egger T, Roth J, Prünte A, Nissen C, et al. Cataract formation after bone marrow transplantation. Ann Intern Med. 1993;119:1175-80.

22. Meier JK, Wolff D, Pavletic S, Greinix H, Gosau M, Bertz H, Lee SJ, Lawitschka A, Elad S. Oral chronic graft-versus-host disease: report from the International Consensus Conference on clinical practice in cGVHD. Clin Oral Investig. 2011;15(2):127-39.
23. Pavletic SZ, Lee SJ, Socie G, Vogelsang G. Chronic graft-versushost disease: implications of the National Institutes of Health consensus development project on criteria for clinical trials. Bone Marrow Transplant. 2006;38(10):645-51.

24. Curtis RE, Metayer C, Rizzo JD, Socié G, Sobocinski KA, Flowers $\mathrm{ME}$, et al. Impact of chronic GVHD therapy on the development of squamous-cell cancers after hematopoietic stem-cell transplantation: an international case-control study. Blood. 2005; 105(10):3802-11

25. Majhail NS, Brazauskas R, Rizzo JD, Sobecks RM, Wang Z, Horowitz $\mathrm{MM}$, et al. Secondary solid cancers after allogeneic hematopoietic cell transplantation using busulfan-cyclophosphamide conditioning. Blood. 2011;117(1):316-22.

26. Rizzo JD, Curtis RE, Socie G, et al. Solid cancers after allogeneic hematopoietic cell transplantation. Blood. 2009;113(5):117583.Comment in: Blood. 2009;114(1):225; author reply 225-6.

27. Holtta P, Alaluusua S, Saarinen-Pihkala UM, Peltola J, Hovi L. Agenesis and microdontia of permanent teeth as late adverse effects after stem cell transplantation in young children. Cancer. 2005; 103(1):181-90.

28. Yen KT, Lee AS, Krowka MJ, Burger CD. Pulmonary complications in bone marrow transplantation: a practical approach to diagnosis and treatment. Clin Chest Med. 2004;25(1):189-201.

29. Filipovich AH, Weisdorf D, Pavletic S, Socie G, Wingard JR, Lee SJ, Martin P, Chien J, Przepiorka D, Couriel D, Cowen EW, Dinndorf P, Farrell A, Hartzman R, Henslee-Downey J, Jacobsohn D, McDonald G, Mittleman B, Rizzo JD, Robinson M, Schubert M, Schultz K, Shulman H, Turner M, Vogelsang G, Flowers ME. National Institutes of Health consensus development project on criteria for clinical trials in chronic graft-versus-host disease: I. Diagnosis and staging working group report. Biol Blood Marrow Transplant. 2005;11(12):945-56.

30. Williams KM, Chien JW, Gladwin MT, Pavletic SZ. Bronchiolitis obliterans after allogeneic hematopoietic stem cell transplantation. JAMA. 2009;302(3):306-14

31. Au BK, Au MA, Chien JW. Bronchiolitis obliterans syndrome epidemiology after allogeneic hematopoietic cell transplantation. Biol Blood Marrow Transplant. 2011;17(7):1072-78.

32. Aleman BM, van den Belt-Dusebout AW, De Bruin ML, van 't Veer $\mathrm{MB}$, Baaijens $\mathrm{MH}$, de Boer JP, et al. Late cardiotoxicity after treatment for Hodgkin lymphoma. Blood. 2007;109:1878-86.

33. Tichelli A, Bucher C, Rovó A, Stussi G, Stern M, Paulussen M, et al. Premature cardiovascular disease after allogeneic hematopoietic stem-cell transplantation. Blood. 2007;110(9):3463-71.

34. Ritchie DS, Seymour JF, Roberts AW, Szer J, Grigg AP. Acute left ventricular failure following melphalan and fludarabine conditioning. Bone Marrow Transplant. 2001;28(1):101-3.

35. Griffith ML, Savani BN, Boord JB. Dyslipidemia after allogeneic hematopoietic stem cell transplantation: evaluation and management. Blood. 2010;116(8):1197-204.

36. National Cholesterol Education Program (NCEP) Expert Panel on Detection, Evaluation, and Treatment of High Blood Cholesterol in Adults (Adult Treatment Panel III). Third Report of the National Cholesterol Education Program (NCEP) Expert Panel on Detection, Evaluation, and Treatment of High Blood Cholesterol in Adults (Adult Treatment Panel III) final report. Circulation. 2002;106(25):3143-421.Comment in: Circulation. 2002;106(25):3140-1, Circulation. 2002;106(25):e9068-8.

37. McDonald GB. Hepatobiliary complications of hematopoietic cell transplantation, 40 years on. Hepatology. 2010;51(4):1450-60.

38. Barshes NR, Myers GD, Lee D, Karpen SJ, Lee TC, Patel AJ, et al. Liver transplantation for severe hepatic graft-versus-host disease: an analysis of aggregate survival data. Liver Transpl. 2005;11(5): 525-31. 
39. Peffault de Latour R, Lévy V, Asselah T, Marcellin P, Scieux C, Adès L, et al. Long-term outcome of hepatitis $\mathrm{C}$ infection after bone marrow transplantation. Blood. 2004;103(5):161824.

40. Majhail NS, Lazarus HM, Burns LJ. Iron overload in hematopoietic cell transplantation. Bone Marrow Transplant. 2008;41(12):9971003.

41. Hingorani S. Chronic kidney disease in long-term survivors of hematopoietic cell transplantation: epidemiology, pathogenesis, and treatment. J Am Soc Nephrol. 2006;17(7):1995-2005.

42. Choi M, Sun CL, Kurian S, Carter A, Francisco L, Forman SJ, et al. Incidence and predictors of delayed chronic kidney disease in longterm survivors of hematopoietic cell transplantation. Cancer. 2008; 113:1580-7.

43. Hingorani S, Guthrie KA, Schoch G, Weiss NS, McDonald GB. Chronic kidney disease in long-term survivors of hematopoietic cell transplant. Bone Marrow Transplant. 2007;39(4):223-9.

44. Syrjala KL, Langer SL, Abrams JR, Storer BE, Martin PJ. Late effects of hematopoietic cell transplantation among 10-year adult survivors compared with case-matched controls. J Clin Oncol. 2005;23(27):6596-606.

45. Herzberg PY, Heussner P, Mumm FH, Horak M, Hilgendorf I, von Harsdorf S, et al. Validation of the human activity profile questionnaire in patients after allogeneic hematopoietic stem cell transplantation. Biol Blood Marrow Transplant. 2010;16(12): 1707-17.

46. Couriel DR, Beguelin GZ, Giralt S, De Lima M, Hosing C, KharfanDabaja MA, et al. Chronic graft-versus-host disease manifesting as polymyositis: an uncommon presentation. Bone Marrow Transplant. 2002;30(8):543-46.

47. Grauer O, Wolff D, Bertz H, Greinix H, Kühl JS, Lawitschka A, et al. Neurological manifestations of chronic graft-versus-host disease after allogeneic haematopoietic stem cell transplantation: report from the Consensus Conference on Clinical Practice in chronic graft-versus-host disease. Brain. 2010;133(10):2852-65.

48. McClune BL, Polgreen LE, Burmeister LA, Blaes AH, Mulrooney DA, Burns LJ, et al. Screening, prevention and management of osteoporosis and bone loss in adult and pediatric hematopoietic cell transplant recipients. Bone Marrow Transplant. 2011;46 (1):1-9.

49. Schulte CM, Beelen DW. Bone loss following hematopoietic stem cell transplantation: a long-term follow-up. Blood. 2004;103(10): 3635-43.

50. Yao S, McCarthy PL, Dunford LM, Roy DM, Brown K, Paplham $\mathrm{P}$, et al. High prevalence of early-onset osteopenia/osteoporosis after allogeneic stem cell transplantation and improvement after bisphosphonate therapy. Bone Marrow Transplant. 2008;41(4): 393-8.

51. Savani BN, Donohue T, Kozanas E, Shenoy A, Singh AK, Childs $\mathrm{RW}$, et al. Increased risk of bone loss without fracture risk in longterm survivors after allogeneic stem cell transplantation. Biol Blood Marrow Transplant. 2007;13(5):517-20.

52. Recommendations for the prevention and treatment of glucocorticoidinduced osteoporosis: 2001 update. American College of Rheumatology Ad Hoc Committee on Glucocorticoid-Induced Osteoporosis. Arthritis Rheum. 2001;44(7):1496-503.

53. Woo SB, Hellstein JW, Kalmar JR. Narrative review: bisphosphonates and osteonecrosis of the jaws. Ann Intern Med. 2006;144(10):753-61.Erratum In: Ann Intern Med. 2006; 145 (3):235.Comment in: Ann Intern Med. 2006;145(10):791; author reply 792, Nat Clin Pract Endocrinol Metab. 2006;2 (12):662-3

54. Park-Wyllie LY, Mamdani MM, Juurlink DN, Hawker GA, Gunraj $\mathrm{N}$, Austin PC, et al. Bisphosphonate use and the risk of subtrochanteric or femoral shaft fractures in older women. Jama.
2011;305(8):783-9.Comment in: Evid Based Med. 2011;16(6): 168-9, J Bone Joint Surg Am. 2011;93(16):1546. JAMA. 2011; 305(20):2068-9; author reply 2069, JAMA. 2011;305(20):2068; author reply 2069.

55. McAvoy S, Baker KS, Mulrooney D, Blaes A, Arora M, Burns LJ, et al. Corticosteroid dose as a risk factor for avascular necrosis of the bone after hematopoietic cell transplantation. Biol Blood Marrow Transplant. 2010;16(9):1231-6. Comment in: Biol Blood Marrow Transplant. 2010;16(12):1750-1.

56. Socié G, Cahn JY, Carmelo J, Vernant JP, Jouet JP, Ifrah N, et al. Avascular necrosis of bone after allogeneic bone marrow transplantation: analysis of risk factors for 4388 patients by the Societe Francaise de Greffe de Moelle (SFGM). Br J Haematol. 1997;97(4):865-70.

57. Sostak P, Padovan CS, Yousry TA, Ledderose G, Kolb HJ, Straube A. Prospective evaluation of neurological complications after allogeneic bone marrow transplantation. Neurology. 2003;60(5): 842-8.

58. de Brabander C, Cornelissen J, Smitt PA, Vecht CJ, van den Bent MJ. Increased incidence of neurological complications in patients receiving an allogenic bone marrow transplantation from alternative donors. J Neurol Neurosurg Psychiatry. 2000;68(1): 36-40.

59. Tichelli A, Rovó A, Passweg J, Schwarze CP, Van Lint MT, et al. Late complications after hematopoietic stem cell transplantation. Expert Rev Hematol. 2009;2(5):583-601.

60. Sostak P, Padovan CS, Eigenbrod S, Roeber S, Segerer S, Schankin $\mathrm{C}$, et al. Cerebral angiitis in four patients with chronic GVHD. Bone Marrow Transplant. 2010;45:1181-8.

61. Booth-Jones M, Jacobsen PB, Ransom S, Soety E. Characteristics and correlates of cognitive functioning following bone marrow transplantation. Bone Marrow Transplant. 2005;36(8):695702 .

62. Syrjala KL, Artherholt SB, Kurland BF, Langer SL, Roth-Roemer $\mathrm{S}$, Elrod JB, et al. Prospective neurocognitive function over 5 years after allogeneic hematopoietic cell transplantation for cancer survivors compared with matched controls at 5 years. J Clin Oncol. 2011;29(17):2397-404.

63. Brennan BM, Shalet SM. Endocrine late effects after bone marrow transplant. Br J Haematol. 2002;118(1):58-66.

64. Sanders JE, Hoffmeister PA, Woolfrey AE, Carpenter PA, Storer $\mathrm{BE}$, Storb RF, et al. Thyroid function following hematopoietic cell transplantation in children: 30 years' experience. Blood. 2009; 113(2):306-8.

65. Ranke MB, Schwarze CP, Dopfer R, Klingebiel T, Scheel-Walter $\mathrm{HG}$, Lang $\mathrm{P}$, et al. Late effects after stem cell transplantation (SCT) in children--growth and hormones. Bone Marrow Transplant. 2005;35(Suppl 1):S77-81.

66. Sanders JE. Endocrine complications of high-dose therapy with stem cell transplantation. Pediatr Transplant. 2004;8(Suppl 5): 39-50.

67. Lee SJ, Flowers ME. Recognizing and managing chronic graftversus-host disease. Hematology Am Soc Hematol Educ Program. 2008:134-41.

68. Spinelli S, Chiodi S, Costantini S, Van Lint MT, Raiola AM, Ravera GB, et al. Female genital tract graft-versus-host disease following allogeneic bone marrow transplantation. Haematologica. 2003; 88(10):1163-8.

69. Zantomio D, Grigg AP, MacGregor L, Panek-Hudson Y, Szer J, Ayton R. Female genital tract graft-versus-host disease: incidence, risk factors and recommendations for management. Bone Marrow Transplant. 2006;38(8):567-72.

70. Metayer C, Curtis RE, Vose J, Sobocinski KA, Horowitz MM, Bhatia S, et al. Myelodysplastic syndrome and acute myeloid 
leukemia after autotransplantation for lymphoma: a multicenter case-control study. Blood. 2003;101(5):2015-23.

71. Landgren O, Gilbert ES, Rizzo JD, Socié G, Banks PM, Sobocinski $\mathrm{KA}$, et al. Risk factors for lymphoproliferative disorders after allogeneic hematopoietic cell transplantation. Blood. 2009;113 (20):4992-5001. Comment in: Blood. 2009;113(24):6263-4.

72. Loren AW, Chow E, Jacobsohn DA, Gilleece M, Halter J, Joshi S, et al. Pregnancy after hematopoietic cell transplantation: a report from the late effects working committee of the Center for International Blood and Marrow Transplant Research (CIBMTR). Biol Blood Marrow Transplant. 2011;17:157-66.

73. Salooja N, Szydlo RM, Socie G, Rio B, Chatterjee R, Ljungman P, Van Lint MT, Powles R, Jackson G, Hinterberger-Fischer M, Kolb HJ, Apperley JF; Late Effects Working Party of the European
Group for Blood and Marrow Transplantation. Pregnancy outcomes after peripheral blood or bone marrow transplantation: a retrospective survey. Lancet. 2001;358(9278):271-6.

74. Child and Adolescent Recommendations. U.S. Preventive Services Task Force. http://www.uspreventiveservicestaskforce.org/tfchild cat.htm (accessed 05/01/2011).

75. Recommendations for Adults. U.S. Preventive Services Task Force. http://www.uspreventiveservicestaskforce.org/adultrec.htm (accessed 05/01/2011).

76. Screening for Osteoporosis, Topic Page. January 2011. U.S. Preventive Services Task Force. http://www. uspreventiveservices taskforce.org/uspstf/uspsoste.htm (accessed 08/01/2011)

77. 2008 Physical activity guidelines for Americans. US Department of Health and Human Services, www.health.gov (accessed 07/15/2011).

$\mathrm{XXX}$

\section{Apendix tables}

\begin{tabular}{|c|c|c|c|}
\hline Vaccine & Recommended for use after HCT & Time post-HCT to initiate vaccine & No. of doses \\
\hline Pneumococcal conjugate (PCV) & Yes & 3-6 months & $3-4^{b}$ \\
\hline Tetanus, diphtheria, acellular pertussis ${ }^{\mathrm{c}}$ & Yes & $6-12$ months & $3^{\mathrm{d}}$ \\
\hline Haemophilus influenzae conjugate & Yes & 6-12 months & 3 \\
\hline Meningococcal conjugate & Follow country recommendations for general population & 6-12 months & 1 \\
\hline Inactivated polio & Yes & 6-12 months & 3 \\
\hline Recombinant hepatitis B & Follow country recommendations for general population & 6-12 months & 3 \\
\hline Inactivated influenza & Yearly & 4-6 months & $1-2^{e}$ \\
\hline Measles-mumps-rubella (live) f $^{\mathrm{f} g}$ & Measles: All children and seronegative adults & 24 months & $1-2^{\mathrm{h}}$ \\
\hline
\end{tabular}

Adapted from: "Guidelines for preventing infectious complications among hematopoietic cell transplantation recipients: A global perspective", Biology of Blood and Marrow Transplantation, Volume 15, Issue 10, Pages 1143-1238, Copyright 2009, with permission from Elsevier; and "Vaccination of hematopoietic cell transplant recipients", Bone Marrow Transplantation, Volume 44, Issue 8, Pages 521-526, Copyright 2009, with permission from Macmillan Publishers Ltd.1 Guidelines for vaccinations considered optional or not recommended for HCT recipients and for vaccinations for family, close contacts and health-care workers of HCT recipients are available from these references.

aA uniform specific interval between doses cannot be recommended as various intervals have been used in studies. As a general guideline, a minimum of 1month between doses may be reasonable.

bollowing the primary series of three PCV doses, a dose of the 23-valent polysaccharide pneumococcal vaccine (PPSV23) to broaden the immune response might be given. For patients with chronic GVHD who are likely to respond poorly to PPSV23, a fourth dose of the PCV should be considered instead of PPSV23

${ }^{\mathrm{C}} \mathrm{DTaP}$ (diphtheria tetanus pertussis vaccine) is preferred, however, if only Tdap (tetanus toxoid-reduced diphtheria-toxoid reduced acellular pertussis vaccine) is available (for example, because DTaP is not licensed for adults), administer Tdap. Acellular pertussis vaccine is preferred, but the whole-cell pertussis vaccine should be used if it is the only pertussis vaccine available

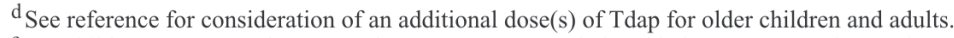

$\mathrm{e}^{\mathrm{e}}$ For children $<9$ years of age, two doses are recommended yearly between transplant and 9 years of age.

${ }^{\mathrm{f}}$ Measles, mumps and rubella vaccines are usually given together as a combination vaccine. In females with pregnancy potential, vaccination with rubella vaccine either as a single or a combination vaccine is indicated

$\mathrm{g}_{\text {Not recommended }}<24$ months post-HCT, in patients with active GVHD and in patients on immune suppression

hIn children, two doses are favored. 
Table B - Recommendations for screening and prevention of late complications in long-term HCT survivors by selected exposures and risk-factors; this table highlights late complications that require greater vigilance or alternate followup schedule in this group of patients in addition to guidelines applicable for all HCT recipients (Table 1)

\begin{tabular}{l} 
Tissues/organs \\
\hline Pediatric HCT recipients \\
Oral \\
Nervous system \\
Endocrine \\
Patients with active or history of chronic GVHD \\
Immune system
\end{tabular}

Ocular

Oral

Respiratory

Muscle and connective tissue

Skeletal

Endocrine

Mucocutaneous

Second cancers

Patients with prolonged pre- or post-transplant corticosteroid exposure Immune system

Muscle and connective tissue

Skeletal

Endocrine

TBI recipients

Mucocutaneous

Second cancers
Monitoring tests and preventive measures

Yearly assessment of teeth development

Annual assessment for congnitive development milestones

Clinical and endocrinologic gonadal assessment for pre-pubertal boys and girls within 1 year of transplant, with further followup as determined in consultation with a pediatric endocrinologist

Monitor growth velocity annually; assessment of thyroid, and growth hormone function if clinically indicated

Antimicrobial prophylaxis targeting encapsulated organisms and PCP for the duration of immunosuppressive therapy

Screening for CMV reactivation should be based on risk factors, including intensity of immunosuppression.

Routine clinical evaluation, and if indicated, ophthalmologic examination more frequently than general recommendations of 6 months, 1 year and yearly thereafter

Consider more frequent oral and dental assesments with particular attention to intra-oral malignancy evaluation compared to general recommendations of 6 months, 1 year and yearly thereafter for clinical oral assessment and 1 year and yearly therafter for dental assessment Some experts recommend clinical evaluation ( \pm PFT's) start before 6 months and occur more frequently than general recommendations of 6 months, 1 year and yearly thereafter Physical therapy consultation in patients with prolonged corticosteroid exposure, fascitis or scleroderma

Frequent clinical evaluation by manual muscle tests or by assessing ability to go from sitting to standing position for patients on prolonged corticosteroids

Some experts recommend dual photon densitometry at an earlier date in patients with prolonged corticosteroid or calcineurin inhibitor exposure compared to general recommendations of 1 year

Slow terminal tapering of corticosteroids for those with prolonged exposure

Consider stress doses of corticosteroids during acute illness for patients who have received chronic corticosteroids

Consider more frequent gynecologic evaluation based on clinical symptoms compared to general recommendations of 1 year and yearly thereafter

Clinical and dental evaluation with particular attention towards oral and pharyngeal cancer

Counsel patients about risks of secondary malignancies annually, particularly of the

oropharynx and skin, and encourage them to perform self exam (e.g., skin)

Antimicrobial prophylaxis targeting encapsulated organisms and PCP for the duration of immunosuppressive therapy

Screening for CMV reactivation should be based on risk factors, including intensity of immunosuppression

Physical therapy consultation

Frequent clinical evaluation by manual muscle tests or by assessing ability to go from sitting to standing position

Some experts recommend dual photon densitometry at an earlier date compared to general recommendations of 1 year

Slow terminal tapering of corticosteroids for those with prolonged exposure

Consider stress doses of corticosteroids during acute illness for patients who have received chronic corticosteroids

Consider more frequent gynecologic evaluation based on clinical symptoms compared to general recommendations of 1 year and yearly thereafter

Screening mammography in women starting at age 25 or 8 years after radiation exposure, whichever occurs later but no later than age 40 
Table C - List of guidelines referenced in this manuscript and links to their websites

\begin{tabular}{|c|c|}
\hline Guideline (Reference) & Sponsor \\
\hline $\begin{array}{l}\text { Long-term followup guidelines for survivors } \\
\text { of childhood, adolescent and young adult cancers }\end{array}$ & Children's Oncology Group (COG) \\
\hline $\begin{array}{l}\text { Guidelines for preventing infectious } \\
\text { complications among hematopoietic cell } \\
\text { transplantation recipients: A global perspective }(9,10)\end{array}$ & $\begin{array}{l}\text { Center for International Blood and Marrow } \\
\text { Transplant Research (CIBMTR), the National } \\
\text { Marrow Donor Program (NMDP), the } \\
\text { European Blood and Marrow Transplant } \\
\text { Group (EBMT), the American Society of } \\
\text { Blood and Marrow Transplantation (ASBMT), } \\
\text { the Canadian Blood and Marrow Transplant } \\
\text { Group (CBMTG), the Infectious Diseases } \\
\text { Society of America (IDSA), the Society for } \\
\text { Healthcare Epidemiology of America (SHEA), } \\
\text { the Association of Medical Microbiology } \\
\text { and InfectiousDiseases Canada (AMMI), } \\
\text { and the Centers for Disease Control and } \\
\text { Prevention (CDC) }\end{array}$ \\
\hline
\end{tabular}

Prevention of infective endocarditis: Guidelines from the American Heart Association ${ }^{(15)}$

American Hearth Association (AHA)

Third report of the expert panel on detection, evaluation and treatment of high blood cholesterol in adults (Adult Treatment Panel III) ${ }^{(36)}$

Physical activity guidelines for Americans ${ }^{(77)}$

Recommendations for the prevention and treatment of glucocorticoid-induced osteoporosis ${ }^{(52)}$

Recommendations for the prevention and treatment of glucocorticoid-induced osteoporosis ${ }^{(52)}$

Preventive health recommendations for adults*

Preventive health recommendations for children and adolescents * (NHLBI) (HHS)
Website Link

http://www.survivorshipguidelines.org/

http://www.ncbi.nlm.nih.gov/pubmed/19747629

http://www.ncbi.nlm.nih.gov/pubmed/19861977 http://circ.ahajournals.org/content/116/15/1736.full.pdf http://my.americanheart.org/professional/StatementsGuidelines /ByTopic/TopicsD-H/Endocarditis_UCM_321487_Article.jsp

National Heart, Lung and Blood Institute

US Department of Health and Human Services

American College of Rheumatology (ACR)

American College of Rheumatology (ACR)

US Preventive Services Task Force (USPSTF)

US Preventive Services Task Force (USPSTF) http://circ.ahajournals.org/content/106/25/3143.long http://www.nhlbi.nih.gov/guidelines/cholesterol/

http://www.health.gov/paguidelines/

http://www.rheumatology.org/practice/clinical/guidelines/ osteoupdate.asp

http://www.rheumatology.org/practice/clinical/guidelines/ osteoupdate.asp

http://www.uspreventiveservicestaskforce.org/adultrec.htm

http://www.uspreventiveservicestaskforce.org/tfchildcat.htm

* Includes guidelines for cancer screening 